Wilfrid Laurier University

Scholars Commons @ Laurier

\title{
A Model for the Development of the Rhizobial and Arbuscular Mycorrhizal Symbioses in Legumes and Its Use to Understand the Roles of Ethylene in the Establishment of these two Symbioses
}

Frédérique C. Guinel

Wilfrid Laurier University, fguinel@wlu.ca

R.D. Geil

Wilfrid Laurier University

Follow this and additional works at: https://scholars.wlu.ca/biol_faculty

\section{Recommended Citation}

Guinel, Frédérique C. and Geil, R.D., "A Model for the Development of the Rhizobial and Arbuscular Mycorrhizal Symbioses in Legumes and Its Use to Understand the Roles of Ethylene in the Establishment of these two Symbioses" (2002). Biology Faculty Publications. 22.

https://scholars.wlu.ca/biol_faculty/22

This Article is brought to you for free and open access by the Biology at Scholars Commons @ Laurier. It has been accepted for inclusion in Biology Faculty Publications by an authorized administrator of Scholars Commons @ Laurier. For more information, please contact scholarscommons@wlu.ca. 


\title{
A model for the development of the rhizobial and arbuscular mycorrhizal symbioses in legumes and its use to understand the roles of ethylene in the establishment of these two symbioses
}

\author{
F.C. Guinel and R.D. Geil
}

\begin{abstract}
We propose a model depicting the development of nodulation and arbuscular mycorrhizae. Both processes are dissected into many steps, using Pisum sativum L. nodulation mutants as a guideline. For nodulation, we distinguish two main developmental programs, one epidermal and one cortical. Whereas Nod factors alone affect the cortical program, bacteria are required to trigger the epidermal events. We propose that the two programs of the rhizobial symbiosis evolved separately and that, over time, they came to function together. The distinction between these two programs does not exist for arbuscular mycorrhizae development despite events occurring in both root tissues. Mutations that affect both symbioses are restricted to the epidermal program. We propose here sites of action and potential roles for ethylene during the formation of the two symbioses with a specific hypothesis for nodule organogenesis. Assuming the epidermis does not make ethylene, the microsymbionts probably first encounter a regulatory level of ethylene at the epidermis - outermost cortical cell layer interface. Depending on the hormone concentrations there, infection will either progress or be blocked. In the former case, ethylene affects the cortex cytoskeleton, allowing reorganization that facilitates infection; in the latter case, ethylene acts on several enzymes that interfere with infection thread growth, causing it to abort. Throughout this review, the difficulty of generalizing the roles of ethylene is emphasized and numerous examples are given to demonstrate the diversity that exists in plants.
\end{abstract}

Key words: AM, epidermis, evolution, pea, rhizobia, sym mutant.

Résumé : Les auteurs proposent un modèle décrivant le développement de la nodulation et des mycorhizes arbusculaires. Ils divisent les processus en plusieurs étapes, en utilisant comme terme de référence des mutants du Pisum sativum L. pour la nodulation. Dans la nodulation, on distingue deux programmes principaux de développement, un épidermique et un cortical. Alors que le facteur Nod seul affecte le programme cortical, les bactéries sont nécessaires pour déclencher les évènements épidermiques. Les auteurs suggèrent que les deux programmes de la symbiose rhizobienne auraient évolué séparément et que, avec le temps, ils en seraient venus à fonctionner ensemble. Cette distinction entre les deux programmes n'existe pas pour le développement des mycorhizes arbusculaires, bien qu'on retrouve des évènements au niveau de ces deux tissus. Les mutations qui affectent les deux symbioses sont restreintes au programme épidermique. Les auteurs proposent des sites d'action et des rôles potentiels pour l'éthylène au cours de la formation des deux symbioses, avec une hypothèse spécifique pour l'organogenèse nodulaire. En assumant que l'épiderme ne produit pas d'éthylène, les microsymbiotes rencontrent probablement, pour la première fois, un niveau régulateur d'éthylène à l'interface entre les couches cellulaires de l'épiderme et du cortex. Selon la teneur en hormone qui s'y trouve, la colonisation va progresser ou avorter. Dans le premier cas, l'éthylène agit sur le cytosquelette du cortex, permettant la réorganisation qui facilite la colonisation; dans le second cas, plusieurs enzymes interfèrent avec la croissance du cordon d'infection, causant l'avortement. Tout au long de cette synthèse, on met l'accent sur la difficulté de généraliser les rôles de l'éthylène et on donne plusieurs exemples qui démontrent la diversité qui existe chez les plantes.

Mots clés : AM, épiderme, évolution, pois, rhizobia, mutant sym.

[Traduit par la Rédaction]

Received 22 November 2001. Published on the NRC Research Press Web site at http://canjbot.nrc.ca on 5 July 2002.

F.C. Guinel ${ }^{1}$ and R.D. Geil. Department of Biology, Wilfrid Laurier University, Waterloo, ON N2L 3C5, Canada.

${ }^{1}$ Corresponding author (e-mail: fguinel@wlu.ca). 


\section{Introduction}

With new genetic approaches (e.g., the use of model plant systems and plant mutants), significant advances have been made in plant physiology, especially in the fields of ethylene (its biosynthesis, signal transduction pathway, and functions) and mutualistic symbioses (nodulation and arbuscular mycorrhizae (AM) formation). In the last decade, new model plant systems have been developed to study these plantmicrobe interactions. Medicago truncatula (barrel medic) was proposed as such by Barker et al. (1990) because it possessed numerous properties that make it the ideal tool for plant physiology; it has a short generation time, high yields, and a relatively small genome and is easily transformable. Later, Sagan et al. (1995) screened nodulation lines of this species for their endomycorrhizal characters. Another model plant also frequently used to study the two symbioses is Lotus japonicus; nodulation mutants of this species have been developed by Szczyglowski et al. (1998) and Schauser et al. (1998). Some of these were further screened for alterations in AM formation (Wegel et al. 1998; Bonfante et al. 2000). These model plants have proven to be invaluable for the indepth study of the symbioses. Unfortunately, these species are of no major agricultural use, so the need to study plants of more economical importance is absolute. Several crop plants are indeed available for study (Table 1); these have been mutagenized and screened for nodulation phenotypes. Our knowledge of their genetics and physiology in addition to their availability makes them priceless (e.g., Sprent 2002). In this review, we draw conclusions from both model and nonmodel plants alike and attempt to organize the developmental steps that ultimately are responsible for the production of nodules and AM. In addition, we propose a role for the hormone ethylene in the establishment of these two symbiotic structures.

\section{Mutualistic symbioses}

In the last decade, numerous reviews have been written on the development of the structures resulting from the interactions between rhizobia and legumes (i.e., nodules) and between AM fungi and plants. Readers are referred to Brewin (1991, 1998), Hirsch (1992), and Hadri and Bisseling (1998) for extensive reviews of nodule organogenesis and Peterson and Farquhar (1994), Bonfante and Perotto (1995), and Harrison (1999) for mycorrhizae formation. The use of mutants has allowed researchers to dissect in detail the morphogenesis of the symbiotic structures, unraveling new steps in the process. Throughout this review, we have relied heavily on the rich pool of existing mutants of Pisum sativum $\mathrm{L}$. (pea). In the text, these mutants are designated only by their sym genes; for further details on their phenotypes, the reader is directed to the references listed in Table 2 .

In this review, we present working models in an attempt to outline the chronological steps required for the organogenesis of a nodule (Fig. 1) and that of AM (Fig. 2). We have tried to dissect these two symbioses in as many welldefined steps as possible but still have kept our diagrams simple to discuss the effects of ethylene on the establishment and development of both symbioses.
Table 1. Crop legumes that have been mutagenized and have mutants available for studying symbioses.

\begin{tabular}{lll}
\hline Common name & Latin name & Reference(s) \\
\hline Pea & Pisum sativum & $\begin{array}{c}\text { Engvild 1987; Kneen and } \\
\text { LaRue 1988; Duc and } \\
\text { Messager 1989; }\end{array}$ \\
& & Borisov et al. 1992 \\
& & Carroll et al. 1986; \\
Soybean & Glycine max & Gremaud and Harper \\
& & 1989; Schmidt et al. 1999 \\
White bean & Phaseolus vulgaris & Park and Buttery 1988 \\
Sweetclover & Melilotus alba & Kneen and LaRue 1988 \\
& annua & Paruvangada and Davis \\
Chickpea & Cicer arietinum & 1999 \\
& & Barnes et al. 1988 \\
Alfalfa & Medicago sativa &
\end{tabular}

\section{Nodule organogenesis}

For the study of nodule organogenesis, we focused on indeterminate nodules, since it has been suggested that this pattern of development could be regarded as the "ground state" of nodulation (Hirsch and LaRue 1997). We chose to depict the process as more or less linear, with a portion comprising two parallel branches that eventually rejoin; one branch pertains only to events occurring in the epidermis whereas the other involves only the cortex (Fig. 1). Where the branching actually takes place is difficult to say; it is possible that the discovery and study of new mutants will define more precisely this important point. To draw the sequence of events, we use plant mutants to which the principle of "first morphological abnormality observed" (Morzhina et al. 2000) was applied; this principle states that if a defect exists in one step, the following stage in the development of the symbiosis does not occur.

To dissect more easily the nodulation developmental program, we divide it into three broad sections: preinfection stages, infection stages, and postinfection stages. Not included in our model are the steps characterizing the function or physiology (e.g., nitrogen fixation) of the nodule, i.e., the steps found after nodule persistence. It is worthwhile to note that all preinfection stages can be triggered by Nod factors (NF) in the absence of rhizobia; NF are complex molecules made by flavonoid-activated bacteria (e.g., Cohn et al. 1997).

\section{Preinfection stages}

\section{Pericycle}

In Medicago sp., cells of the pericycle (the outermost layer of the vascular tissue) are among the first to respond to NF by undergoing microtubular cytoskeleton (Csk) rearrangement (Timmers et al. 1999). In pea, rhizobia activate the early nodulin (ENOD) gene PsENOD40 in the pericycle cells (Fig. 1) closest to the nodule progenitor cells (e.g., Yang et al. 1993). Interestingly, this gene is also expressed in that tissue upon treatment of transgenic Medicago sativa (alfalfa) by cytokinins (plant hormones involved in cell division; Fang and Hirsch 1998). Also, transgenic Nicotiana tabacum (tobacco) protoplasts expressing ENOD40 exhibit an altered sensitivity to auxin (van de Sande et al. 1996). 
Table 2. List of pea mutants, their mutated loci, and their symbiotic phenotypes.

\begin{tabular}{|c|c|c|c|c|}
\hline Pea mutant & Locus & $\begin{array}{l}\text { Nod and (or) } \\
\text { myc phenotype }\end{array}$ & Nodulation reference & Mycorrhiza reference \\
\hline \multirow[t]{2}{*}{ Afghanistan } & "Afg" & Strain specific & Le Gal and Hobbs 1989 & \\
\hline & $\operatorname{sym} 2 A$ & Strain specific & Geurts et al. 1997 & \\
\hline JI1357 & sym3 & $\operatorname{Nod}^{+} \mathrm{fix}^{-}$ & Borisov et al. 2000 & \\
\hline E2 & sym5 & Low nod/myc ${ }^{++}$ & Guinel and LaRue 1991 & $\begin{array}{l}\text { C. Albrecht (personal } \\
\text { communication) }\end{array}$ \\
\hline E69 & sym7 & $\mathrm{Nod}^{-}$ & Kneen et al. 1994 & \\
\hline $\mathrm{R} 25$ & sym8 & $\mathrm{Nod}^{-} / \mathrm{myc}^{-}$ & Markwei and LaRue 1992 & Balaji et al. 1994 \\
\hline $\mathrm{R} 72, \mathrm{P} 54$ & sym 9 & $\mathrm{Nod}^{-} / \mathrm{myc}^{-}$ & Markwei and LaRue 1992 & Balaji et al. 1994 \\
\hline P56 & sym10 & $\mathrm{Nod}^{-} / \mathrm{myc}^{+}$ & Sagan et al. 1994 & Duc et al. 1989 \\
\hline K5 & sym12 & Low nod & Postma et al. 1988 & \\
\hline E135F & sym13 & $\mathrm{Nod}^{+} \mathrm{fix}^{-} / \mathrm{myc}^{+}$ & Kneen et al. 1990 & Balaji et al. 1994 \\
\hline SGENod $^{-}-2$ & sym 14 & $\mathrm{Nod}^{-}$ & Tsyganov et al. 1999 & \\
\hline R50 & sym16 & Low nod/myc $\mathrm{my}^{+}$ & Guinel and Sloetjes 2000 & $\begin{array}{l}\text { R. Landewert, R.L. Peterson, } \\
\text { and F.C. Guinel (data not } \\
\text { shown) }\end{array}$ \\
\hline $\mathrm{R} 82$ & sym17 & Low nod & Lee and LaRue $1992 a$ & \\
\hline P6, P55 & sym19 & $\mathrm{Nod}^{-} / \mathrm{myc}^{-}$ & Sagan et al. 1994 & Duc et al. 1989 \\
\hline E132 & sym 21 & Low nod & Markwei and LaRue 1997 & \\
\hline P61 & sym 25 & $\operatorname{Nod}^{+}$fix $^{-}$ & Duc et al. 1989 & \\
\hline P63 & sym 26 & $\operatorname{Nod}^{+}$fix $^{-}$ & Duc et al. 1989 & \\
\hline $\mathrm{P} 12$ & sym 27 & $\mathrm{Nod}^{+} \mathrm{fix}^{-}$ & Duc et al. 1989 & \\
\hline P53 & sym30 & $\mathrm{Nod}^{-} / \mathrm{myc}^{-}$ & Sagan et al. 1994 & Duc et al. 1989 \\
\hline Sprint-2Fix ${ }^{-}$ & sym31 & $\operatorname{Nod}^{+}$fix $^{-}$ & Borisov et al. 1997 & \\
\hline RisFixL & sym32 & $\operatorname{Nod}^{+}$fix $^{-}$ & $\begin{array}{l}\text { Engvild 1987, as cited in } \\
\text { Borisov et al. } 2000\end{array}$ & \\
\hline SGEFix $^{-}-2$ & sym33 & $\operatorname{Nod}^{+}$fix $^{-}$ & Tsyganov et al. 1998 & \\
\hline RisNod1 & sym 34 & $\mathrm{Nod}^{-}$ & Borisov et al. 2000 & \\
\hline SGENod $^{-}-4$ & sym35 & $\mathrm{Nod}^{-} / \mathrm{myc}^{+}$ & Tsyganov et al. 1999 & Madsen et al. 2001 \\
\hline RisNod24 & sym36 & $\mathrm{Nod}^{-} / \mathrm{myc}^{-2}$ & $\begin{array}{l}\text { Engvild 1987, as cited in } \\
\text { Borisov et al. } 2000\end{array}$ & $\begin{array}{l}\text { Gianinazzi-Pearson et al. } \\
1991\end{array}$ \\
\hline RisNod4 & sym37 & $\mathrm{Nod}^{-}$ & $\begin{array}{l}\text { Engvild 1987, as cited in } \\
\text { Borisov et al. } 2000\end{array}$ & \\
\hline RisFixF/SGENod ${ }^{-}-4$ & sym38 & $\mathrm{Nod}^{-}$ & $\begin{array}{l}\text { Engvild 1987, as cited in } \\
\text { Borisov et al. } 2000\end{array}$ & \\
\hline P57 & sym39 & Low nod & Sagan et al. 1994 & \\
\hline SGEFix $^{-}-1$ & sym 40 & $\operatorname{Nod}^{+}$fix $^{-}$ & Tsyganov et al. 1998 & \\
\hline RisFixA & sym 41 & $\operatorname{Nod}^{+} \mathrm{fix}^{-}$ & $\begin{array}{l}\text { Engvild 1987, as cited in } \\
\quad \text { Borisov et al. } 2000\end{array}$ & \\
\hline E107 & $b r z$ & Low nod/low myc & Guinel and LaRue 1992 & Resendes et al. 2001 \\
\hline
\end{tabular}

The product of the ENOD40 gene can be considered as a plant growth regulator that modulates the sensitivity of the plant to auxin (Cohn et al. 1997) and possibly to cytokinin. Charon et al. (1997) suggested that ENOD40 diffuses from the pericycle to the inner cortical cells, altering their auxincytokinin balance and inducing mitoses.

\section{Epidermis}

Epidermal cells, especially root hairs $(\mathrm{RH})$, also respond to the NF; the tips of the hairs swell, giving them a spatulated appearance. This alteration could be explained by a change in their osmotic pressure (Fig. 1); it has been shown that RH swell at their tips when their turgor pressure is increased, i.e., when the osmotic pressure of the external medium decreases (Ekdahl 1953). This step allows us to differentiate the sym 8 and sym19 nonnodulating pea mutants
(Figs. 1 and 3); inoculated sym8 mutants do not exhibit RH deformations (Markwei and LaRue 1992) whereas inoculated sym19 mutants have spatulated hairs (Sagan et al. 1994). As these physical changes occur at the RH tip, numerous chemical adjustments take place on either side of the RH plasma membrane. Not indicated on the model are electrophysiological changes such as membrane depolarization and alkalinization measured in alfalfa RH tips by Felle et al. (1995) and Felle et al. (1996), respectively. However, the first event to be detected is a calcium influx at the RH tip, an event recently reviewed extensively (Cardenas et al. 2000; Lhuissier et al. 2001). Independent of these changes in calcium concentrations is a process known as calcium spiking (Fig. 1) described by Walker et al. (2000) as the repeat of sharp momentary oscillations in intracellular calcium levels. This phenomenon is quite localized and appears to be 
Fig. 1. Model depicting the events triggered in the host legume, either by NF alone or by rhizobia, during the development of an indeterminate nodule. The process appears to have two main branches, one representing an epidermal program (shaded boxes) and the other a cortical program (dashed boxes). For the events of the epidermal program to be triggered, the physical presence of rhizobia is required. RH, root hair; IT, infection thread, PIT, preinfection thread.

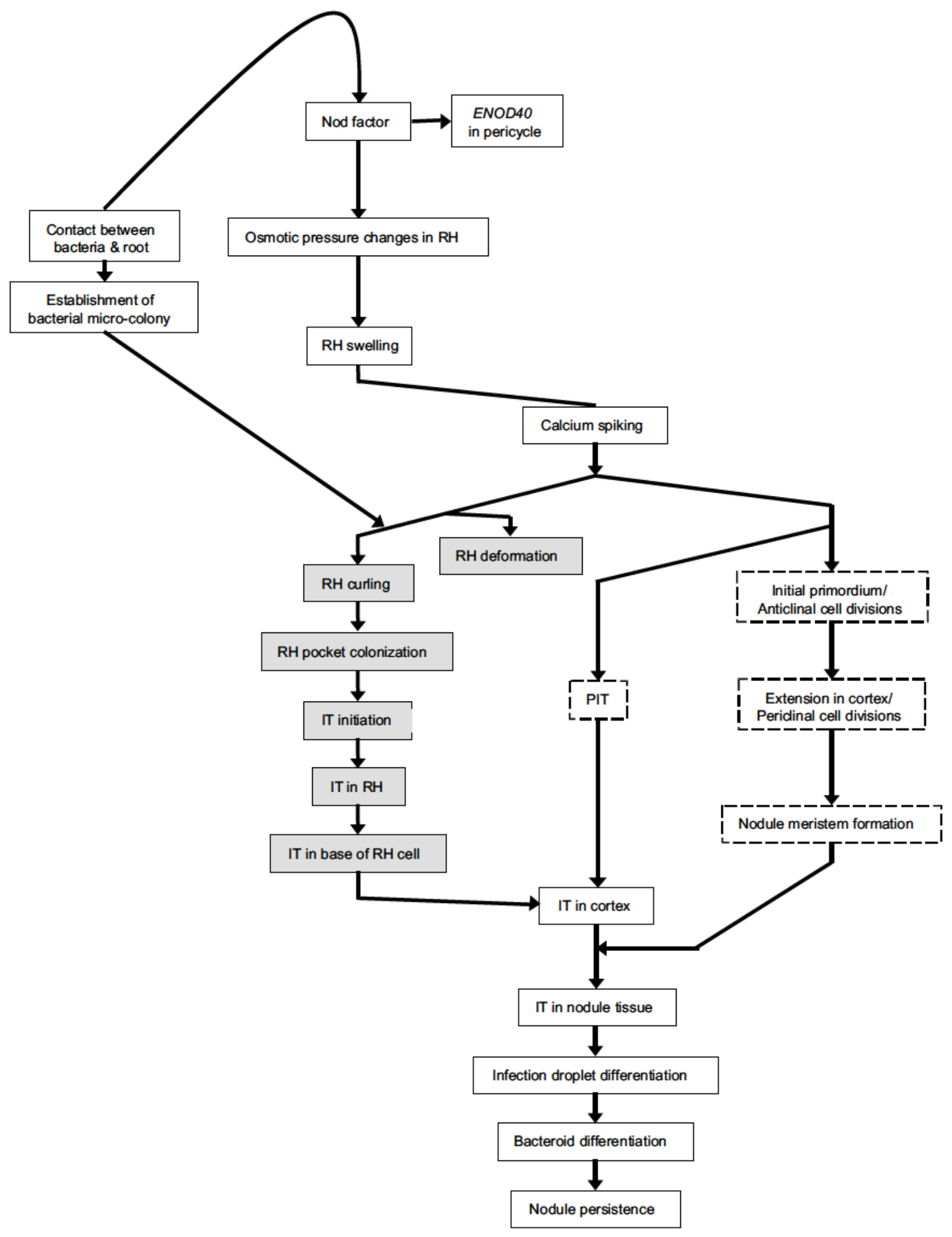


Fig. 2. Model depicting the events triggered in a host plant during the formation of Arum-type arbuscular mycorrhizas (AM).

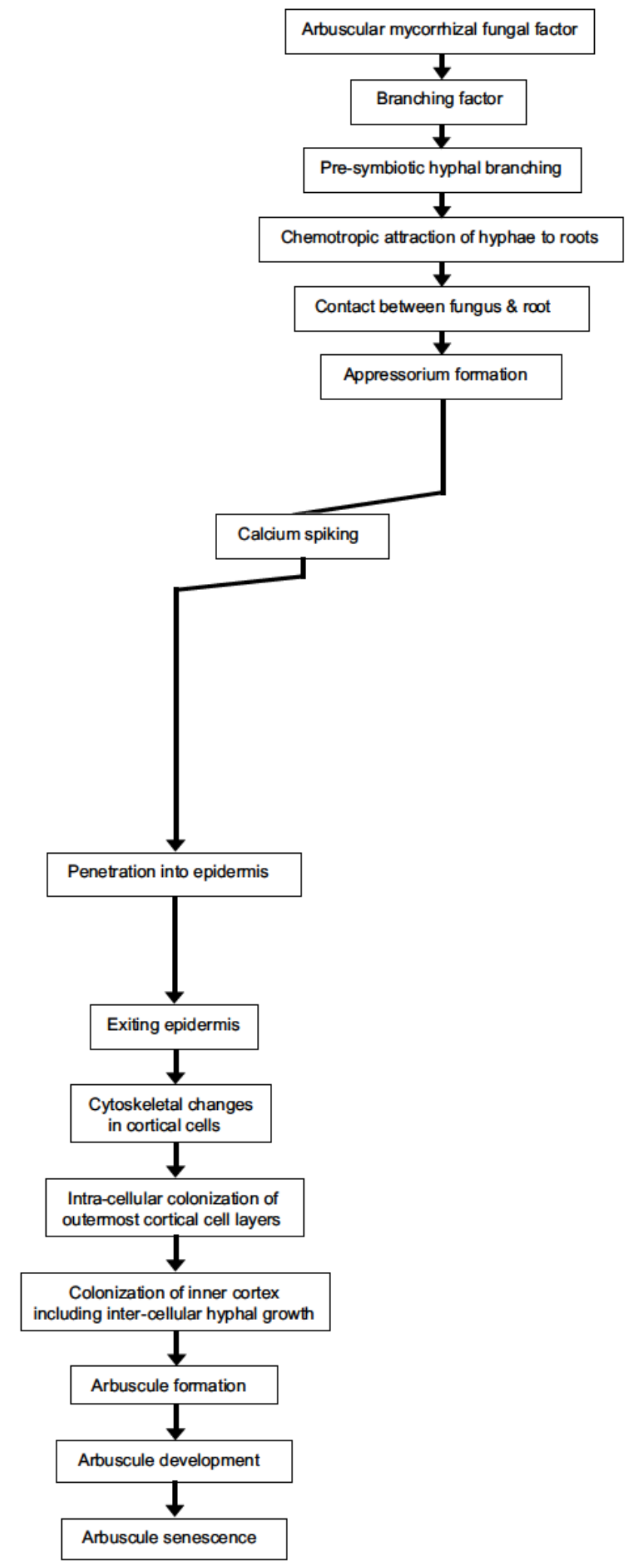

restricted to the perinuclear area of $\mathrm{RH}$ (Ehrhardt et al. 1996).

\section{Cortex}

Finally, the cells of both the inner and outer cortex respond to NF. Within the inner cortex, new gene expression occurs as a response; for example, specific cells mainly located opposite the protoxylem poles express the ENOD $M s E N O D 12 A$ in alfalfa (Bauer et al. 1996) and MtENOD20 in barrel medic (Vernoud et al. 1999). The cell cycles of these inner cortical cells in addition to certain outer cortical cells are concomitantly reactivated. While the progenitor cells of the nodule primordium (NP) continue the cell cycle, those of the outer cortex are arrested in the G2 phase (Yang et al. 1994). The progenitor cells divide first anticlinally (Bauer et al. 1996; Guinel and Sloetjes 2000) to form the initial primordium (Fig. 1); they then divide several times periclinally to form the NP and meristem (Fig. 1). Within cells of the outer cortex, following cytoplasmic rearrangement, the nucleus migrates to the centre while cytoplasmic bridges form in alignment with the anticlinal walls of the dividing inner cortical cells (van Brussel et al. 1992; Timmers et al. 1999). The formation of these bridges, called preinfection threads (PIT) (van Brussel et al. 1992), is reminiscent of that of the phragmosome (Rae et al. 1992) which usually occurs before mitosis; PIT are thought to pave the way through the cortex for the bacteria-filled infection threads (IT) (Fig. 1).

\section{Processes common to epidermis and cortex}

Calcium fluctuations likely affect both epidermal and cortical cells either directly as for the RH (see above) or indirectly through ubiquitous physiological processes. Calcium acts as a secondary signal in the defence response, an event thought to occur transiently during rhizobial infection (e.g., Vasse et al. 1993). Recently, the study of the sym 30 pea mutant (Blilou et al. 1999) reemphasized such a response; $48 \mathrm{~h}$ after inoculation, this nonnodulating mutant, able to sense NF and to exhibit calcium spiking in its $\mathrm{RH}$, accumulates large amounts of salicylic acid in its roots. Blilou et al. (1999) propose that, in a normal symbiosis, the defence response is quickly suppressed, allowing for the symbiosis to be established. Calcium is also known to influence the Csk; at low concentrations, calcium ions stabilize peripheral microtubules whereas they destabilize them at higher concentrations (Reddy 2001). Changes in microtubules have to be occurring both in the epidermis, to allow RH to further deform, and in the cortex, to allow cell division and cell preparation for bacterial entry. The levels of calcium are likely to be regulated by plant hormone, which we think, as others do (e.g., Kolchinsky et al. 1994), have a role in early nodule organogenesis. Hormones act in at least two locations, the epidermis and the cortex. For example, ethylene acts specifically at the epidermis in pea (Lee and LaRue 1992c) whereas changes in auxin levels precede the divisions of the nodule progenitor cells in the inner cortex of Trifolium repens (white clover) roots (Mathesius et al. 1998).

\section{Infection stages}

All of the stages described up to this point can be triggered by purified NF alone. However, the physical presence of the rhizobia is required for $\mathrm{RH}$ to curl (Catoira et al. 
Fig. 3. Model combining Figs. 1 and 2 and outlining the genetic dissection of the two organogeneses. All mutants shown here have been characterized and references can be found in Table 2 . The mutants, the loci of which are underlined, indicate myc ${ }^{+}$, those in bold are $\mathrm{myc}^{-}$or low myc, and those in regular font have yet to have their mycorrhiza phenotype determined. The preinfection thread step (see Fig. 1) has been removed for simplification. RH, root hair; IT, infection thread.

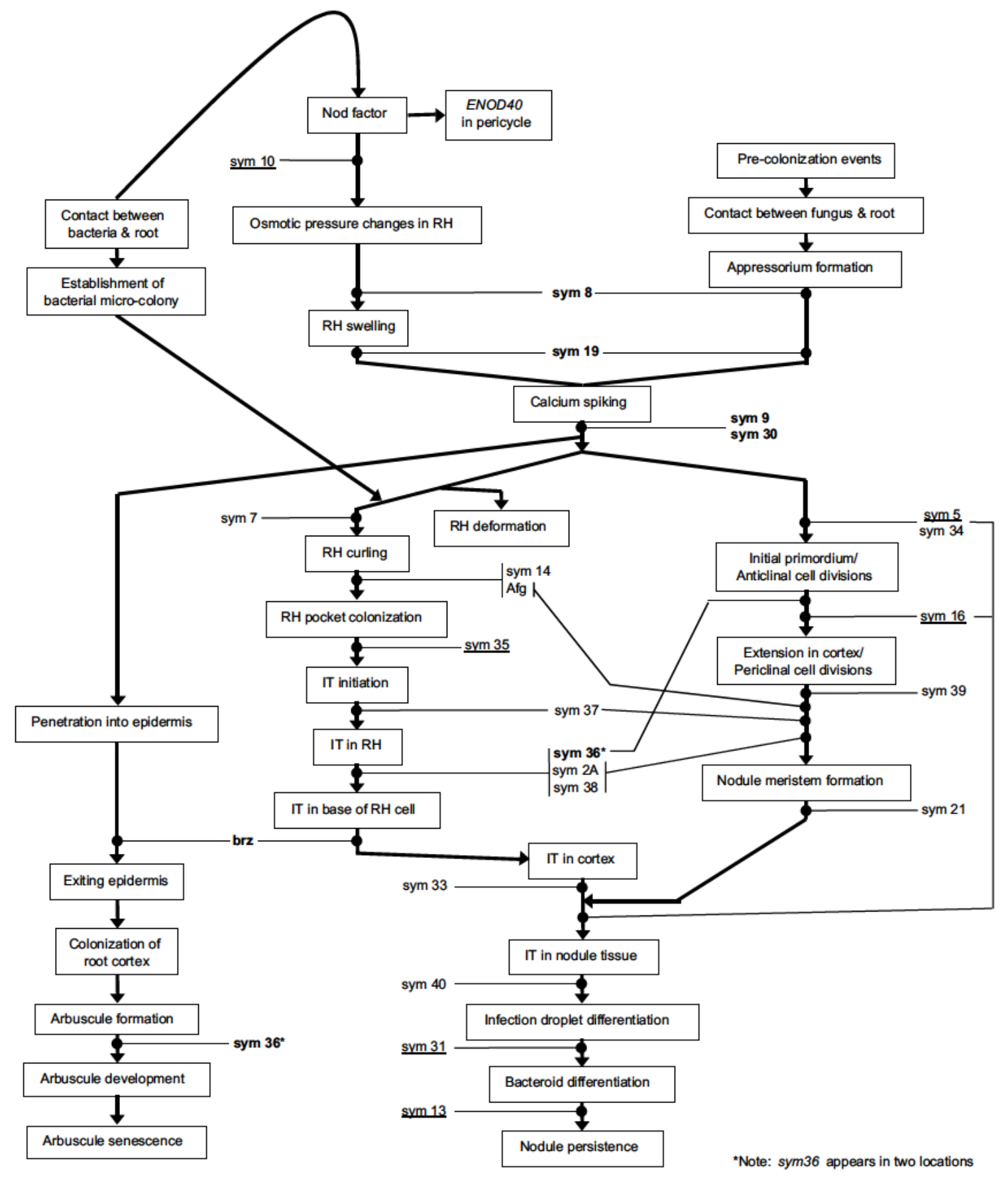

2001) and for IT to form (van Brussel et al. 1992). In the absence of rhizobia, the NF signals are not strong enough to stimulate $\mathrm{RH}$ curling and the subsequent epidermal program. Ardourel et al. (1994) suggested that two types of NF receptors exist; the entry receptor has a strict requirement for a specific NF structure whereas the signaling receptor is less discriminating. We further propose that upon binding of the NF to the entry receptor, the RH door would open to the bacteria, leading to the induction of the events of the epidermal program (Fig. 1). Upon binding to the signaling receptor, only $\mathrm{RH}$ deformation and events of the cortical program would be triggered (Fig. 1). Although progress has been made in the search for these receptors (Niebel et al. 1999), their existence is still elusive. Our model supports Schneider et al. (1999) who proposed that the nodulation process is composed of two parts, the first part thought to 
mediate specifically the response to the Rhizobium signals (our epidermal program) and the other part encompassing the entire nodule formation (our cortical program).

Recently, two groups focused their work on the entry per se of the rhizobia. Tsyganov et al. (2002) and Catoira et al. (2001) included an additional step to this already complex process, that of colonization of curled RH pockets (Fig. 1); however, the two groups disagree on the temporal location of this step. The question is whether the RH forms the curl on its own (Tsyganov et al. 2002) or whether the rhizobia act physically on the host root to form the curl (Catoira et al. 2001). If the former is true, a bacterial colony would establish itself in the chamber formed by the curl; the colony, while growing, would put pressure on the host wall, partially breaking it, and enter into the cell. If the latter occurs, the bacteria would play an active role in directing the curl. Catoira et al. (2001) proposed that, once the bacteria are in contact with the RH, one microcolony takes over and directs the rearrangement of the microtubules in that cell, in effect directing the growth of the curl. Emons and Mulder (2000) hypothesized that at the site of rhizobial attachment, RH tip growth is stimulated and takes a new direction. Because of the continuous release of NF and the proliferation of the rhizobia over time, the change of direction is constantly occurring; in effect, the orientation of the growth rotates and a curl forms, entrapping the bacterial colony.

Although the mechanism by which the rhizobia enter the $\mathrm{RH}$ is not entirely understood, enzymatic digestion appears to be prevalent, at least in white clover (Mateos et al. 2001). As the IT is initiated, Csk rearrangement leads to the nucleus migrating to the base of the RH (Timmers et al. 1999); the IT is now unimpeded to grow towards the cortex (Fig. 1). For the IT to form and expand, the plant cell has to coordinate secretion of matrix, plasma membrane, and cell wall components (Rae et al. 1992). The breaching of the outer cortex by the IT appears to be one of the most important checkpoints in the development of this symbiosis (e.g., Guinel and LaRue 1992; Resendes et al. 2001) (also see below).

\section{Postinfection stages}

The late stages of our model have been described by Brewin (1998), Timmers et al. (1998), Borisov et al. (2000), and Voroshilova et al. (2001). Upon entering the cortex, the IT follows the path delineated by the PIT (Fig. 1); it passes from cell to cell by degrading the walls of the cortical cells. van Spronsen et al. (1994) proposed that this wall degradation is a two-step process; whereas NF predispose the periclinal walls to breaching, the rhizobia within the IT are required for the breakdown of the wall to occur. Simultaneously with IT growth in the outer cortex, inner cortical cells continue to divide to form the NP. Through the organized activity of a meristem (Fig. 1), the nodule grows to reach its mature size at which time several histological zones are distinguished (Vasse et al. 1990).

Once the IT reaches the infection zone (Vasse et al. 1990), the rhizobia enter the cell by endocytosis in an infection droplet surrounded by a symbiosome membrane (Fig. 1) (Brewin 1998). Recently infected cells undergo reorganization of their microtubules, probably in preparation for the arrival of the microsymbionts (Davidson and Newcomb 2001b); the cells increase in size and their DNA endoreduplicates (Timmers et al. 1998). Bacteria, in the droplet, undergo differentiation and become bacteroids (Fig. 1). The bacteroids divide in the droplet as the symbiosome membrane is synthesized; this ensures that the number of bacteroids per symbiosome, dependent on the plant species, remains constant (Brewin 1998). The bacteroids are now able to undertake nitrogen fixation once they have adapted to the host cytoplasmic environment. In older infected cells, changes to the actin microfilaments of the host cells have also been observed (Davidson and Newcomb 2001a).

\section{A few imperfections of our model}

Some processes, such as nodulin expression (Pawlowski 1997) and hormonal alterations, occur throughout nodule development and therefore cannot be placed accurately on our model. In fact, these two processes appear to be linked and the expression of some ENOD genes follows alterations in hormonal levels. For example, cytokinins act on MsEnod12A expressed in alfalfa (Bauer et al. 1996) and on SrEnod2 expressed in Sesbania rostrata (Dehio and de Bruijn 1992).

Although our model emphasizes the existence of two distinct developmental programs, these are not uncoupled (Figs. 1 and 3). For a proper indeterminate nodule to be established, not only must signal(s) be transduced linearly along the two programs (our model) but additional signals must be sent from the IT tip, where rhizobia are present, to the NP (and (or) vice versa) (Timmers et al. 1999). Exactly what happens, with respect to communication, between the IT in the outer cortex and the NP in the inner cortex is still a mystery. Should we assume that NF are continuously synthesized by the rhizobia, even in planta (Timmers et al. 1998), and that they have a different function depending on their locale of production? Or should we consider the NF as being mainly extraradical molecules that, upon their binding, send signals triggering different events along a pathway (e.g., Mylona et al. 1995)?

The pea mutant sym36 (DK24; Sagan et al. 1994) exemplifies the molecular dialogue existing between the two branches. sym 36 is characterized by an abnormally large IT that aborts before reaching the base of the epidermal cell; furthermore, few cell division centres are observed in the inner cortex and these do not proceed to form an NP (Sagan et al. 1994). The nodulation phenotype of sym36 could be explained by a lack of communication between the epidermal and cortical programs (Fig. 3); one of the required signals could be missing or not perceived by one (or both) region(s). Not surprisingly, the steps involving communication between the two programs all occur once rhizobial infection per se has begun (Fig. 3), suggesting that for the two programs to work together, bacteria have to be present; the bacterial signals, e.g., internalized NF (Timmers et al. 1998), probably make the link between the two zones.

\section{Epidermal and cortical programs of nodulation}

\section{Independence of the programs}

The epidermal and cortical developmental programs, although not uncoupled from each other, are quite independent. That the two programs are distinct is emphasized by the 
Fig. 4. (B-G) Diagram illustrating the different modes of entry used by rhizobia to infect the root cortex of host legumes and for comparison, $(\mathrm{A}$ and $\mathrm{H}$ ) two processes that do not involve the physical presence of the bacteria. (A) Spontaneous nodule, entirely devoid of rhizobia, can form in the root cortex. (B) In Gleditsia triancanthos, a Caesalpinioideae (the oldest legume subfamily), rhizobia enter the RH via an IT; no NP is ever formed and the rhizobia fix nitrogen within the IT. (C) In Mimosa scabrella, a Mimosoideae, rhizobia enter the cortex intercellularly between the epidermal cells; in response to the infection, an NP forms in the inner cortex. As the rhizobia get closer to it, they become intracellular and an IT-like structure develops. (D) In Neptunia natans, a Mimosoideae, rhizobia enter a crack between two epidermal cells at the base of a lateral root. As a response to infection, an NP is formed. As the bacteria move intercellularly towards it, the path that they take narrows in width and they enter the nodule cells via an IT. (E) In Arachis hypogaea, a Papilionoideae, rhizobia enter the intercellular space at the base of an RH; the base of that RH is always enlarged. The infection always occurs at a lateral root junction and the NP (not depicted) develops in the outer cortex of the lateral root. IT are never observed. (F) In Chamaecytisus proliferus, a Papilionoideae, rhizobia enter via an IT within a curled RH and trigger cell divisions in the inner cortex. The infection appears to abort in the RH or the epidermis quite rapidly after induction of the NP; however, a new intercellular infection occurs close by. (G) In Pisum sativum, a Papilionoideae, rhizobia trigger a shepherd's crook to form while the inner cortical cells divide and organize in an NP. They enter the RH through an IT, which progresses towards the NP. (H) In pea, NF alone can trigger the events of the cortical program stimulating RH branching, initiation of NP formation, and PIT formation (all marked by an asterisk). Ep, epidermis; NP, nodule primordium; VT, vascular tissue; the cortex is located between the epidermis and the vascular tissue. The light grey shading indicates that the bacteria are in an infection thread, whereas the dark grey shading locates them intercellularly. A dashed line represents a preinfection thread.

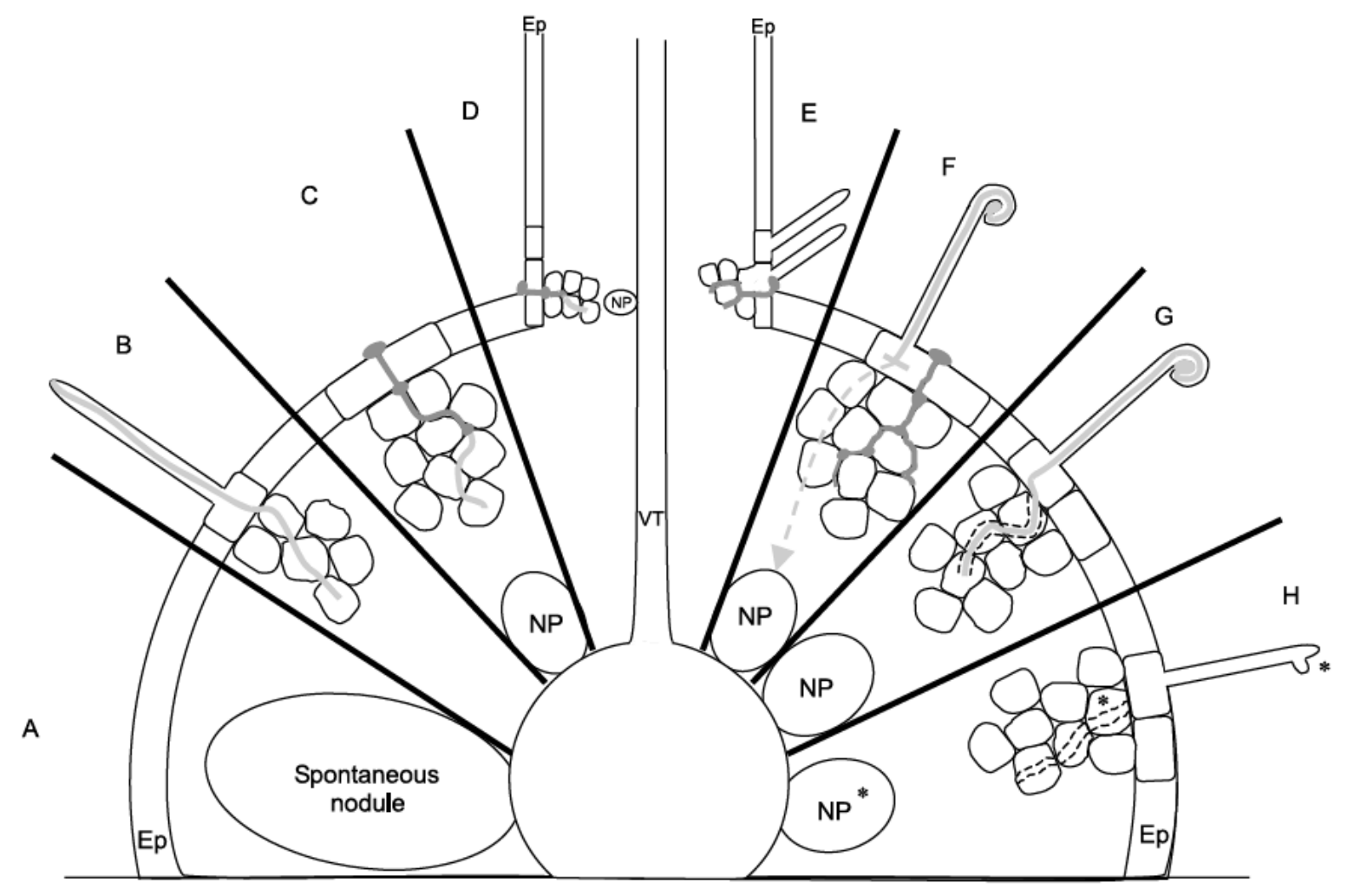

existence of several mutants with defects restricted to either one of the two programs (e.g., sym 35 for the epidermal program or sym 39 for the cortical program; Fig. 3). Although the origin of spontaneous nodules (structures similar to nodules but entirely devoid of bacteria; Fig. 4A) is far from clear, we believe that their existence could be additional evidence for a definite separation of the two programs. In alfalfa, these spontaneous nodules initiate from cell divisions in the inner cortex; these divisions are at first anticlinal and then periclinal (Joshi et al. 1991) as in a symbiotic nodule. All tissues present in the rhizobial nodule (e.g., meristem, cortex, endodermis, and vascular strands) are also observed in these spontaneous nodules (Joshi et al. 1991). Thus, the cortical program can function on its own. More evidence pointing to the independence of the cortical program is that
NF alone are sufficient to induce divisions in the inner cortex and PIT formation in the outer cortex (Fig. 4H) (van Brussel et al. 1992). It is thought that portions of the cortical program of nodule organogenesis could have been borrowed from other morphological processes such as lateral root development (e.g., Hirsch and LaRue 1997; Mathesius et al. 2000).

\section{Coevolution of the two programs}

Several excellent reviews have been written on the evolution of nodulation (e.g., Young and Johnston 1989; Sprent and Raven 1992; Hirsch and LaRue 1997; Provorov et al. 2002). Here, we would like to emphasize the importance of the epidermis in the success of this symbiosis and propose that the cortical and epidermal programs of nodule organo- 
genesis evolved independently from one another. Because NP are present in most rhizobia-legume associations (Fig. 4), and because spontaneous nodules could have been useful to the plant as storage organs (Hirsch and LaRue 1997), it is highly probable that the nodule architecture was in place early in the evolution of legumes, possibly before rhizobia began to associate with them. Thus, the cortical program may have evolved before the epidermal program. If this were the case, it would explain why the mechanisms by which rhizobia enter into the root vary so greatly among legume species whereas the cortical program does not appear to be so flexible (Fig. 4). In those species where the cortical program (with all its hormonal controls) was already in place in the root, the bacteria had simply to develop a way to breach the epidermis. Once the communication was properly established between the two programs, the simple nitrogen-fixing IT (Fig. 4B) could have evolved to a highly efficient nitrogen-fixing organ (Fig. 4G).

Infection is proposed to have evolved independently of nodule formation (Hirsch and LaRue 1997; Parniske 2000); how can this hypothesis be reconciled with the two developmental programs occurring in indeterminate nodule formation? What is referred to as nodule formation appears to correlate with the cortical program; as for the infection and its rhizobia, they deal primarily with the epidermis (Fig. 4), which is logical because the microsymbionts will first encounter the root surface.

\section{Examples illustrating the coevolution of the two programs}

In Gleditsia triancanthos (honey locust), bacterial infection seems to use only the epidermal program (Fig. 4B); the symbiosis does not appear to require the formation of an NP. The bacteria enter the roots via an RH through an IT-like structure (Hirsch and LaRue 1997). They never leave this structure where nitrogen is thought to be fixed; no NP or nodule is ever observed (de Faria et al. 1999, as cited in Parniske 2000).

Rhizobia can also penetrate into the cortex in between two epidermal cells via the anticlinal walls, as in Mimosa scabrella (de Faria et al. 1988) (Fig. 4C). Further penetration occurs through intercellular spaces and primary cell walls; but when close to the NP, the infection becomes intracellular with the bacteria in thread-like structures (Sprent and Raven 1992). Nodules are initiated as in the case of the indeterminate nodules, i.e., in the inner cortex (de Faria et al. 1988).

In Neptunia natans, rhizobial entry is through a crack formed by the emergence of a lateral root (Subba-Rao et al. 1995) (Fig. 4D). As the rhizobia enter through the epidermis, an NP initiates deep in the lateral cortex. The rhizobia follow an intercellular path, at first quite large but that narrows as the rhizobia approach the NP. However, when the rhizobia enter the nodule tissue, it is via an IT (Fig. 4D); once in the nodule cells, the fate of the bacteria is similar to that of rhizobia infecting pea (Subba-Rao et al. 1995).

In Arachis hypogaea (peanut), the rhizobia also enter through spaces occurring between epidermal cells (Boogerd and van Rossum 1997) (Fig. 4E). The nodules develop at lateral root junctions where axillary $\mathrm{RH}$ formed; these do not appear per se to play a role in the infection, but their enlarged bases are required (Boogerd and van Rossum 1997). No IT are observed; the bacteria progress through the cortex by gradually degrading the cells they invade. Nodule initials divide repeatedly in the lateral root cortex to form a nodule.

In Chamaecytisus proliferus (tagasaste), the rhizobia enter deformed RH, travel within an IT (Fig. 4F), and predispose the inner cortical cells to form an NP (Vega-Hernandez et al. 2001). The growth of the IT stops within the RH but the rhizobia then shift to a crack-entry mode to access the cortex and the NP. They reach this zone via an intercellular route, finally entering the dividing cells by altering their walls (Vega-Hernandez et al. 2001). Nodules are not restricted to lateral root axils but develop along the lateral roots as in pea (Vega-Hernandez et al. 2001). This association between tagasaste and Bradyrhizobium sp. is strong evidence for an intermediary stage between the two developmental programs. The bacteria try one method of epidermal entry, triggering the cortical events, but switch to another mechanism to breach the inner epidermal checkpoint. Finally, rhizobia can penetrate via IT in the RH, with subsequent formation of an NP in the inner cortex developing into a nodule (in pea; Fig. 4G) (e.g., Guinel and LaRue 1991).

\section{Mode of entry determined by the plants}

We believe that the macrosymbiont is the main actor in the epidermal entry play because a single type of bacterium can use different mechanisms to enter into different species. For example, one rhizobial strain can enter Vigna unguiculata (cowpea) through RH but peanut through crack entry (Sen and Weaver 1984); this is reminiscent of what occurs in mycorrhizae formation where an AM fungus can form either a Paris-type or an Arum-type pattern of colonization depending on the host (Smith and Read 1997). In the latter, however, the "choice" appears to be made at the epidermis-cortex interface.

Ultimately, the mechanism of entry depends on the chemistry of the epidermal wall. Mort and Grover (1988), studying the sugar composition of $\mathrm{RH}$ cell walls, demonstrated that among legumes, the RH carbohydrate composition did not differ much; on the contrary, there was a large variation when legumes were compared with nonlegumes. This difference among families was further emphasized by Matthysse and McMahan (2001) who studied the attachment of Agrobacterium tumefaciens to RH. AttR mutants of Agrobacterium tumefaciens are able to differentiate $\mathrm{RH}$ of nonlegumes from those of legumes; the bacterium is unable to attach to the former whereas it binds to the latter (Matthysse and McMahan 2001). Since Agrobacterium is closely related to Rhizobium (Young and Johnston 1989), especially Rhizobium leguminosarum and Rhizobium meliloti, it is plausible to assign a similar behaviour to Rhizobium. These differences in bacterial behaviour probably rely on differences in wall chemistry.

The legumes studied by Mort and Grover (1988) all belong to the Papilionoideae subfamily; it would be now very interesting to study the composition of the epidermal walls of more primitive species of legumes such as Gleditsia and Mimosa. It is probable that differences exist among species of the three subfamilies. All in all, it is intriguing that during evolution, rhizobia did not choose the path of least resistance for root entry (i.e., crack entry). We propose that the plant did not let them take that path; it was to the advantage 
of the plant to establish clear checkpoints, each with a tight control. We hypothesize later that cortical entry is under the control of the hormone ethylene.

\section{AM formation}

Two main patterns of cortical tissue colonization (Parisand Arum-type) are possible depending on the host (Gallaud 1905; Smith and Smith 1997) and (or) fungal species (Cavagnaro et al. 2001) involved in a particular association. The Paris-type morphology is characterized by intracellular progression of fungal hyphae towards the inner cortical tissue and the formation of hyphal coils and arbusculate coils (i.e., coils with intercalary fine branches). In contrast, the Arum-type pattern involves both intra- and intercellular hyphal growth towards the inner cortex and along the longitudinal axis of the root with hyphal coils being less prominent and terminal arbuscules being formed on trunk hyphae. For the purpose of this review, we will discuss only the Arum-type morphology because it is this pattern that generally occurs in crop plants (Smith and Read 1997). We based our AM development model (Fig. 2) on our nodule organogenesis model and on the particular defects exhibited by AM formation mutants, which have been compiled in a very useful table by Marsh and Shultze (2001). There is strong indirect evidence that nodulation and AM formation share at least some steps of the signal transduction pathway resulting in the development of symbiotic structures (Duc et al. 1989; van Rhijn et al. 1997; Hirsch and Kapulnik 1998; Albrecht et al. 1999).

Our discussion of AM formation is divided into three broad sections: precolonization stages, colonization stages, and postcolonization stages. These sections correspond loosely to the three main regulatory stages of the colonization process presented by Stougaard (2001): epidermal penetration, colonization of the cortex, and arbuscule formation. However, from our knowledge of nodulation mutants, we believe that two more stages should be added, that of exiting the epidermis and that of arbuscule development. As in the nodulation section, here, we are not considering the events regulating arbuscule function.

\section{Precolonization stages}

For AM to form, a recognition event involving the exchange of signals must take place between the symbionts (Peterson and Farquhar 1994). Although its details are unclear, this event results in the host identifying the AM fungus as a nonpathogen and in the AM fungal hyphae branching profusely (Fig. 2) and irregularly, presumably to increase the chance of contact with the root. Whereas the former response suggests the involvement of an AM fungal factor (Fig. 2), the latter indicates that a host root factor is also involved. Whatever the branching factor (Fig. 2) exuded by the host roots may be, it is not a flavonoid component (Buée et al. 2000) and it weighs less than $500 \mathrm{Da}$ (Giovannetti et al. 1996).

Subsequent to recognition, physical contact occurs via chemotropic attraction (Fig. 2) of the hyphae to the host roots. Upon contact, the fungus produces a swollen structure, the appressorium, to aid in root entry via the epidermis (Fig. 2); the formation of this structure is the first sign of a compatible association. Appressoria commonly form in the groove between two adjacent files of epidermal cells (Garriock et al. 1989); their formation appears to involve both chemical and topographical signaling between the symbionts (Giovannetti et al. 1993; Nagahashi and Douds 1997).

Although calcium spiking has not yet been observed in response to AM fungi, Walker et al. (2000) found a strong correlation between symbiotic phenotypes and the presenceabsence of calcium spiking (Fig. 2), which led them to suggest that calcium spiking may be a common step in the development of the two symbioses. Fluctuations in the levels of various host hormones occur during the formation of appressoria; for example, the concentrations of both auxins and salicylic acid increase at very early stages of root colonization (Ludwig-Müller 2000). Additionally, ethylene production must be regulated so that a strong defence response by the host is not induced. Gianinazzi-Pearson (1996) has reviewed this type of response, which appears to be under tight control because it occurs only in a weak, transient, and localized manner. The role of this response is not yet fully understood and it may not necessarily be related to a defence mechanism. For example, Salzer et al. (2000) have demonstrated that AM-specific chitinases induced in mycorrhizal barrel medic differ from those expressed in the same species challenged with either Rhizobium or pathogenic fungi.

\section{Colonization stages}

Once an appressorium (Fig. 2) is formed, a combination of enzymatic and mechanical processes occurs allowing the entry of the fungal hyphae into the epidermis. In pea and many other hosts, AM fungi enter the root tissue by producing short hyphae (often referred to as penetration pegs) from appressoria; these penetrate the root between two adjacent epidermal cells and commonly breach one of the cells through its anticlinal wall (Garriock et al. 1989). Interestingly, AM fungi can also enter the root via direct penetration of RH (reviewed by Guinel and Hirsch 2000), in which case the appressoria are not usually formed by the fungus; this is likely because the $\mathrm{RH}$ wall is much thinner and easier to penetrate than a nonhair epidermal cell wall. Genre and Bonfante (2002), studying AM colonization in Lotus japonicus, reported that the epidermal cell Csk is not altered significantly by fungal entry; however, hyphae become surrounded by microtubules and actin microfilaments. In addition, the nucleus, which in noninfected epidermal cells is usually located along one of the periclinal walls, moves closer to the AM fungal wall (Genre and Bonfante 2002).

In pea, once the fungal hypha has reached the inner periclinal wall of an epidermal cell, its diameter decreases before it exits (Fig. 2) and enters the outermost layer of the cortex where the hypha returns to its original diameter (e.g., Geil et al. 2001). It then proceeds towards the inner cortical tissue via an intracellular route. Host microtubules reorganize (Fig. 2) as cortical cells are colonized by AM fungi (Genre and Bonfante 1997; Matsubara et al. 1999). Genre and Bonfante (2002) observed only a slight alteration of the peripheral Csk upon colonization of the outer cortical cells of Lotus japonicus; yet, as in the epidermis, actin bundles and microtubules reorganize to surround the fungal hyphae. In addition, Blancaflor et al. (2001) recently demonstrated in barrel medic that Csk modifications actually occur before 
the fungus enters the cell, which suggests the exchange of a signal in advance of cell penetration. This "takeover" of plant cell growth by a microsymbiont is reminiscent of what occurs in the rhizobial symbiosis during RH curling (see above). Upon reaching the inner cortex, the fungal hyphae enter the intercellular spaces; this allows for a rapid spreading of the hyphae along a significant length of the root (Fig. 2). Eventually, the hyphae reenter the cells of the innermost cortex where they form thick intracellular trunks that branch dichotomously; the resulting structures, the arbuscules (Fig. 2), are considered the main site of nutrient exchange between the symbionts. Dramatic alterations of the Csk occur when the arbuscules are developing (Genre and Bonfante 2002).

\section{Postcolonization stages}

Any time the fungus is within a plant cell, it is separated from the host cytoplasm by a perifungal membrane and an interfacial matrix (Bonfante and Perotto 1995); these two components comprise the interface compartment, which is where bidirectional nutrient transfer occurs. Thus, it is likely that the site of nutrient exchange is not limited to the arbuscule, as all intracellular, and perhaps even intercellular, hyphae are equipped with an interface compartment (Smith and Read 1997). Arbuscules are ephemeral structures, the degeneration of which may provide added nutrients to the host cells that they temporarily occupy. Spreading of colonization units along the longitudinal axis of a root occurs concomitantly with repeated arbuscule formation in the inner cortex over time. In pea and other hosts, structures called vesicles form; these balloon-shaped structures contain lipids and are considered storage reservoirs.

\section{Location of mutant defects on a developmental scale}

In this section, we limit our discussion to pea because organogenesis in, and mutants of, this species have been studied extensively by us and others (e.g., Tsyganov et al. 2002). Here, we incorporate the loci of known mutations in an overall model (Fig. 3), obtained by combining the two diagrams presented earlier (Figs. 1 and 2), in a manner similar to what has been done recently for the very early stages of infection (Catoira et al. 2000; Wais et al. 2000; Walker et al. 2000). With the discovery and characterization of new mutants, the complexity of the organogenesis of symbiotic structures becomes more apparent; with each new phenotype characterized, a novel step is interwoven into the developmental process. In our model, whereas each individual step of nodule formation is based on the existence of one or several mutants, steps depicting AM formation are still quite speculative (Fig. 3). This is because to date, the study of AM mutants lags behind that of nodulation mutants, as seen in Table 2; only those mutants well characterized are included in our model.

According to our model (Fig. 3), one step (calcium spiking) is shared by both symbioses. This step occurs quite early developmentally and its position fits with the hypothesis made by several authors that signals released by the mycorrhizal fungi could activate a transduction pathway used by NF (Albrecht et al. 1998, 1999; Hirsch and Kapulnik 1998). That numerous nod ${ }^{-}$mutants are also myc ${ }^{-}$ provides more argument for this hypothesis and for LaRue and Weeden's (1994) proposal that nodulation could have evolved at least partially from the AM association. For a convincing indication of a shared mechanism(s) among the two symbioses, more mycorrhizal mutants need to be isolated; also, each common step needs to be studied in detail and each mycorrhizal phenotype has to be characterized thoroughly and accurately. Studies of physiological processes should also be undertaken before asserting commonalities between steps of the two symbioses. For example, Blilou et al. (1999) studied the sym30 mutant with a different perspective; they demonstrated that the resistance of this mutant to both symbioses was linked to a root accumulation of free salicylic acid (SA). The amplitude of the response to both microsymbionts was greater than that of the wild-type and increased over time (Blilou et al. 1999). In addition, the SA increase in sym30 was specific to mutualistic organisms (i.e., it did not occur in a pathogenic association); the sym30 gene therefore appears to suppress an SAdependent defence response (Blilou et al. 1999).

From examining the reports discussing the properties of myc $^{-}$mutants, it is evident that a clear and uniform method of characterization is needed. As emphasized in Peterson and Guinel (2000), the temporal and developmental blocks of each mutant should be precisely described with appropriate designation (see Table 3.1 in Smith and Read 1997). For example, the myc ${ }^{-1}$ designation currently comprises mutants with differing phenotypes; these mutants exhibit a colonization block either at the root surface or within the epidermal cell layer (the fungus penetrates the epidermis but cannot exit). The sym 8 and sym 9 mutants (both considered myc ${ }^{-1}$ ) exhibit appressoria formation $\left(\mathrm{app}^{+}\right)$but penetration of the epidermis by the AM fungus never occurs (pen ${ }^{-}$), indicating a root surface block (Balaji et al. 1994; Albrecht et al. 1998). Although the sym30 mutant (also myc $\mathrm{m}^{-1}$ ) is considered a pen mutant (Gianinazzi-Pearson 1996; Marsh and Schultze 2001), colonization of this mutant occasionally includes short infective hyphae originating from appressoria; however, these abort very quickly (Gollotte et al. 1993). Similarly, the sym19 mutant is regarded as a pen ${ }^{-}$mutant (Marsh and Schultze 2001), but Duc et al. (1989) indicated that penetration of the epidermis could occur in this mutant; hyphae could sometimes occupy a few cells before colonization was aborted. Thus, we believe that sym19 could be placed further down in our model (Fig. 3), closer to epidermis penetration; sym 30 would then be involved at an intermediate temporal location.

\section{Epidermis-cortex interface}

\section{Epidermis}

The loci controlling both nodulation and AM formation (in bold in Fig. 3) mostly regulate steps involving the epidermal program. In only one case (sym36) does a mutant link the cortical program of nodulation with AM development. As mentioned earlier, sym36 has abnormal IT and few dividing inner cortical cells (Sagan et al. 1994); upon fungal colonization, it forms stumpy arbuscules (Gianinazzi-Pearson et al. 1991). The fungal hypha enters the cortical cell and differentiates into an arbuscular trunk, but no branches form. It is possible that with the characterization of more mutants, other loci similar to that of sym36 will be found. It is also 
possible that nodulation mutants affected in their cortical program will not be blocked in the development of mycorrhiza because the AM fungi invade roots without triggering any events in the cortex. For example, the sym16 mutant is able to form perfectly normal arbuscules ( $\mathrm{R}$. Landewert, R.L. Peterson, and F.C. Guinel, data not shown), although it is blocked in its nodulation at the start of NP formation (Guinel and Sloetjes 2000). Most of the loci controlling the steps of the nodulation cortical program appear not to affect mycorrhiza formation (Fig. 3). The epidermis seems to act as a cortical gate-keeper both for rhizobia and for AM fungi.

\section{Distinguishing features of epidermal and cortical cells}

That the epidermal cells can be distinguished from the cortical cells by both rhizobial and fungal microsymbionts is not surprising. They are different in their lineages (Fahn 1986) and in their cell wall structure and biochemistry. For example, in Allium porrum (leek), different carbohydrate epitopes are found in the epidermal versus the cortical cell wall matrices (Balestrini et al. 1996). In an artificial system using isolated carrot cells, appressoria formed on epidermal walls but not on cortical walls (Nagahashi and Douds 1997). Epidermal and cortical cells can also be distinguished by gene expression; for example, upon rhizobial inoculation, a peroxidase gene (ripl) is induced specifically in the epidermal cells of barrel medic (Cook et al. 1995) whereas the nodulin MtENOD20 is expressed only in the nodule progenitor cells of the inner cortex (Vernoud et al. 1999). The existence of cell-specific protein markers raises the question of target cells (Osborne 1984) that respond in a specific way to hormonal signals. An example applying to the symbioses would be that of the effect that cytokinins have on the inner cortex; alfalfa roots treated with this hormone exhibit few anticlinal cell divisions only in their inner cortex, reminiscent of the divisions observed after NF treatment (Bauer et al. 1996). Another example is that of ethylene; ethylene does not appear to interfere with bacterial entry into the epidermis but is inhibitory to the formation of an NP (van Spronsen et al. 1995). Finally, these cells differ metabolically; Heidstra et al. (1997) very elegantly showed, by in situ hybridization, that only the cells of the inner cortex facing the phloem poles were expressing 1-amino-cyclopropane-1-carboxylic acid (ACC) oxidase, the enzyme that catalyzes the last step of the ethylene biosynthetic pathway. Similarly, the epidermal cells can undertake metabolic steps that are specific to them (e.g., steps involved in the synthesis and secretion of mucilage).

\section{Interface as a tight checkpoint}

A hot spot exists where numerous mutations (sym36, sym $2 A$, and sym38) affect the same step, that at which the IT progresses from the $\mathrm{RH}$ to the basal part of the epidermal cell. These loci also seem to control two steps in the cortical program (Fig. 3). The epidermal layer indeed represents a strict checkpoint, as indicated by Bonfante et al. (2000) for Lotus japonicus, that exerts a great deal of regulatory control over the development of the two symbioses because another sensitive step is the breaching of the inner periclinal wall of the epidermis (see below). Even in wild-type pea, numerous IT abort in the base of the epidermal cell (Guinel and LaRue 1992). Additional evidence for tight regulation of both nodulation and AM fungal colonization at this point is given by the brz mutant, in which the parallel between the two plant-microbe interactions is striking (Resendes et al. 2001). In each symbiosis, there is a similar reduction in the number of infections, a block at the epidermis-cortex interface, and a few successful infections and the two phenotypes are controlled by the shoot. Control at this interface has also been reported in species other than pea; Wegel et al. (1998), who studied AM formation in Lotus japonicus nodulation mutants, termed mutants with a block at this level $\mathrm{Coi}^{-}$for cortex invasion. Bonfante et al. (2000) further studied these mutants and reported the LjSym4-1 and LjSym4-2 phenotypes. The LjSym4-1 phenotype is very similar to that of the brz pea mutant (Resendes et al. 2001), except in LjSym4-1, a root surface block is not evident. The LjSym4-2 mutant exhibits a much stronger block to epidermal exit in that AM do not form because hyphae never exit the epidermis (Bonfante et al. 2000). Recently, Genre and Bonfante (2002) proposed that LjSym4 is critical in establishing the proper rearrangement of the Csk in the epidermis; its correct expression would allow the AM fungus to cross the epidermal layer without any obstruction. Thus, we can conclude with certainty that the epidermis, especially at its interface with the cortex, is a strong checkpoint in AM colonization (Geurts et al. 1997; Bonfante et al. 2000; Senoo et al. 2000; Resendes et al. 2001).

\section{Effects of ethylene on the two symbioses}

Some reviews have dealt primarily with the regulation of the formation of the two organs (for nodules: CaetanoAnolles 1997; Schultze and Kondorosi 1998; Stougaard 2000; for AM: Barker et al. 1998; Peterson and Guinel 2000); others have focused specifically on the roles of phytohormones in the organogenesis and the regulation of these symbioses, with an emphasis on auxin and cytokinin (e.g., for nodulation: Hirsch and Fang 1994; Hirsch et al. 1997; for AM: Barker and Tagu 2000; Ludwig-Müller 2000). As for ethylene, it is considered an inhibitor (Hirsch and Fang 1994) at least in some legumes such as Phaseolus vulgaris (bean) (Grobbelaar et al. 1971) and pea (Drennan and Norton 1972).

For several decades now, ethylene has been reported to affect the morphology of a plant and to act at any stage of its development. It is surprising to us that reviews on ethylene (e.g., Smalle and van der Straeten 1997; Johnson and Ecker 1998) referred to its effects on symbioses only in an anecdotal manner. We are aware of only one review that mentions the effects of ethylene on both symbioses; this review (Lynch and Brown 1997) on plant responses to nutritional stress indicates briefly and very generally how the two interactions, known to assist the nutritional status of plants under stress, are affected by ethylene. Ethylene is seen as an important hormone, involved in several steps of nodule organogenesis, negatively regulating the initial steps of the developmental process as well as nodule senescence and abscission (Lynch and Brown 1997). Its role in the development of mycorrhizal associations is more difficult to pinpoint; Lynch and Brown (1997) suggested that it could help a plant to distinguish a beneficial symbiont from a pathogen. 
Fig. 5. Signal transduction pathway of ethylene. When ethylene receptors are active, CTR1 inhibits EIN2 and prevents it from acting in gene transcription. When ethylene is present, it binds to the receptor with the help of copper; upon binding, ethylene inhibits CTR1, which then suppresses its action on EIN2. EIN2 is thus free to trigger the transcription of genes, the action of which will stimulate or inhibit physiological responses specific to ethylene. Modified from Solano and Ecker (1998) and Chang and Shockey (1999).

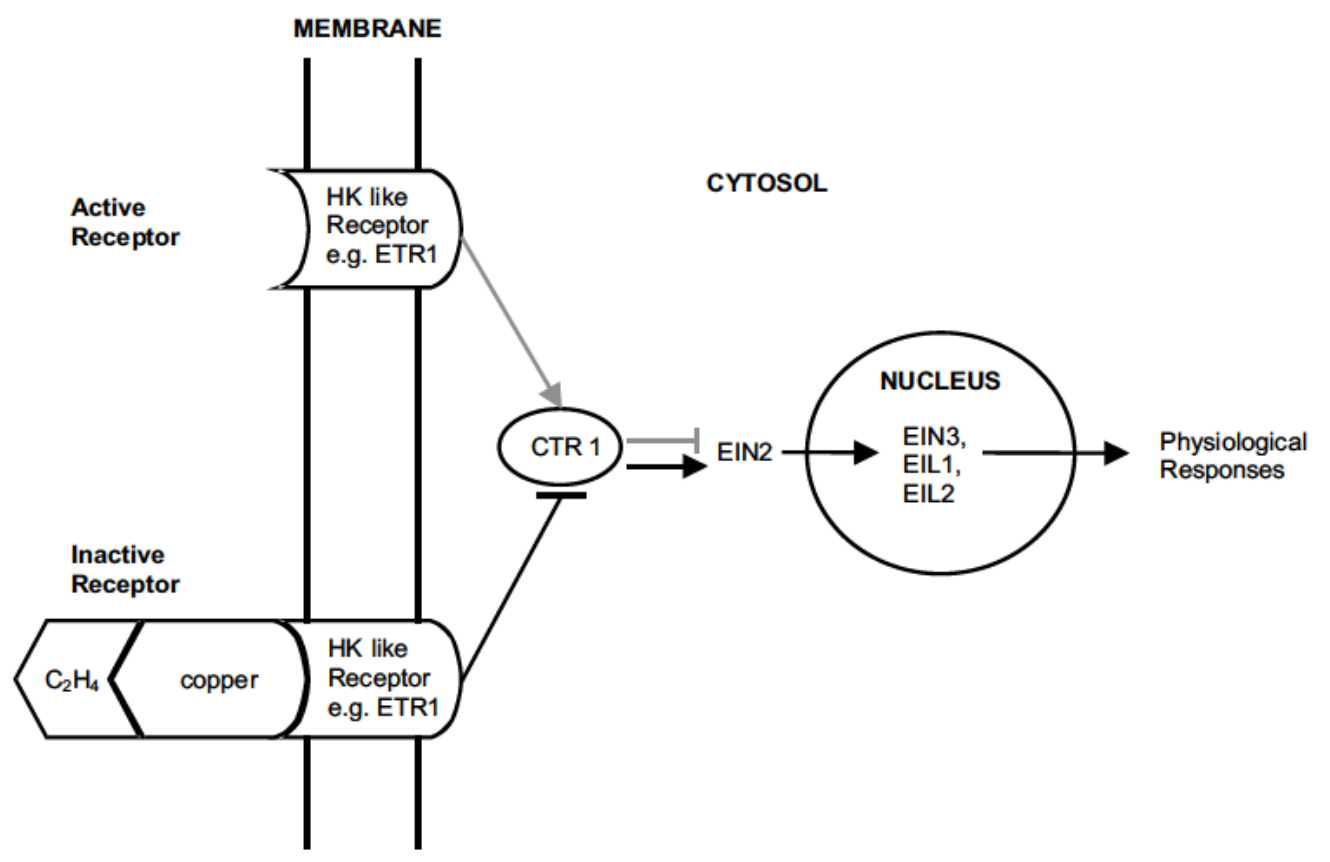

\section{Signal transduction pathway of ethylene}

Since the identification of ACC oxidase, the enzyme catalyzing the conversion of ACC to ethylene (Hamilton et al. 1991), tremendous progress has been made in understanding how this plant hormone is perceived and how the signal it generates is transduced. In a recent review, Hirayama and Alonso (2000) gave a glimpse of the dynamics involved in the perception of this gaseous hormone that is so simple in its chemical structure. For ethylene to be perceived by histidine kinase-like receptors (Fig. 5), copper is required (e.g., Rodriguez et al. 1999). In their active state (i.e., when ethylene is absent), the receptors negatively regulate the downstream components of the transduction pathway (e.g., Chang and Shockey 1999). It is only upon ethylene binding that the receptors become inactive (Hua and Meyerowitz 1998) and repress the constitutive triple response (CTR1) protein, the first component of the transduction pathway. Once the CTR1 protein is repressed, it no longer inhibits the action of the ethylene-insensitive (EIN2) gene products (Fig. 5). The signal is therefore able to move, through a possible mitogen-activated protein kinase cascade (e.g., Solano and Ecker 1998) (Fig. 5), to the nucleus where EIN2 proteins are able to trigger the transcription of several genes that, together, regulate the ethylene response (Theologis 1998).

Our understanding of the ethylene transduction pathway is quite advanced. This path appears quite linear (Fig. 5), but as other signals are discovered and their transduction pathways unraveled, it will turn out to be linked quite intricately with these pathways. The resulting network of pathways allows for better integration and coordination of the signals. An example of such a convergence would be that of the glucose signaling pathway interacting with the ethylene signal transduction pathway (Zhou et al. 1998). Another example is that of the interaction between cytokinin and ethylene (Fuchs and Lieberman 1968); cytokinin promotes ACC synthase (Fig. 6) in a posttranscriptional manner (Vogel et al. 1998), and cytokinin treatments to roots were shown to result in ethylene production (e.g., Lorteau et al. 2001). The main challenge now lies in correlating this molecular knowledge with the cellular and physiological functions of ethylene. As findings are reconciled between physiologists and molecular biologists, this model will become even more complex (Hall et al. 1999). Another challenge will be to understand the mechanism(s) by which ethylene receptors act; there are more than one type of ethylene receptor in many plant species, and we now have to comprehend the role that each one plays (Ciardi and Klee 2001). With respect to ethylene and its role in symbioses, it is quite possible that more than one type of receptor is involved, the action of each allowing the distinction among pathogens and beneficial microbes. The host plant could also respond differentially to different cues by altering its levels of ethylene. For a better understanding of the complexity underlying ethylene receptors, the reader is referred to Ciardi and Klee (2001).

\section{Effects of ethylene on nodulation}

\section{Direct evidence of inhibitory effects}

To our knowledge, the first report of the inhibitory action of ethylene on nodulation was made by Grobbelaar et al. (1971) who studied the effects of carbon dioxide and ethylene applied to roots of bean. These authors found that $0.4 \mu \mathrm{L}$ ethylene/ $\mathrm{L}$ reduced not only the number of nodules formed but also the amount of atmospheric nitrogen fixed by the existing nodules. This inhibitory effect of ethylene was further extended to the nodulation of pea (Drennan and 
Fig. 6. Simplified biosynthetic pathway of ethylene, at least as it is known to occur in the root cortex of higher plants. Whereas AVG (aminoethoxyvinylglycine), a synthetic compound, and rhizobitoxine, a natural bacterial toxin, are inhibitors of ACC synthase, cytokinin, a plant hormone, stimulates the expression of this enzyme. Cobalt or salicylic acid inhibit ACC oxidase, the enzyme responsible for the last step of the pathway, whereas silver is an antagonist of ethylene action. Modified from Abeles et al. (1992).

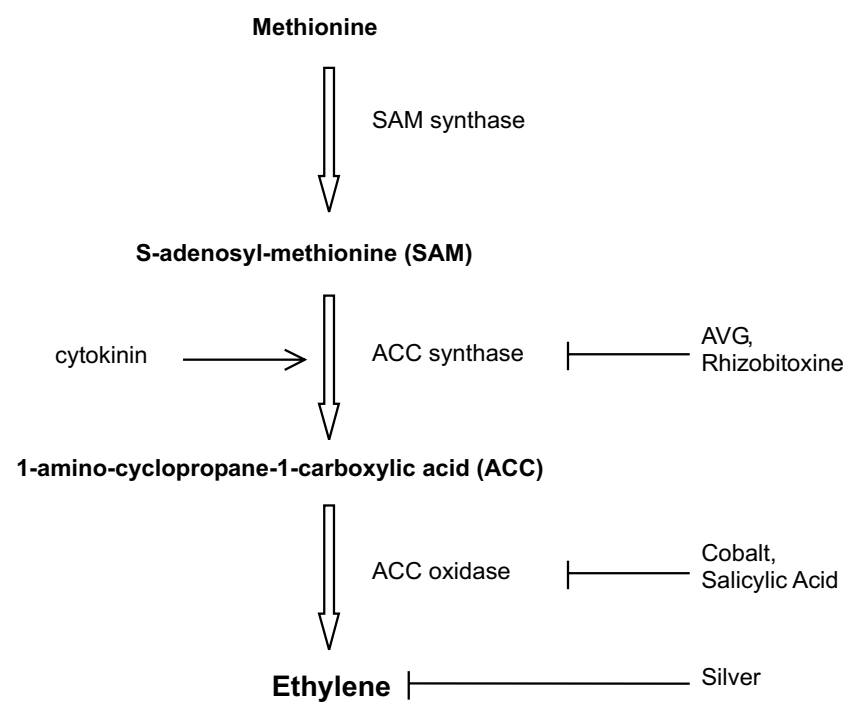

Norton 1972) and white clover (Goodlass and Smith 1979). In each of these studies, the experimental system presented a flaw that made the results less convincing. For example, Grobbelaar et al. (1971) used excised roots that would have produced endogenous wound ethylene. Drennan and Norton (1972) added ethephon (ethrel ${ }^{\circledR}$ ), an ethylene-releasing compound, to the nutrient solution and were then unable to determine the exact amount of ethylene given to the roots. In addition, ethrel is known to be hydrolyzed into ethylene, water, and phosphate (Abeles et al. 1992); thus, the observed effects were not necessarily due to ethylene. Finally, although Goodlass and Smith (1979) were aware of these problems and wanted to treat intact plants with only the roots exposed to ethylene, they applied the gas to the roots 4 weeks after planting and inoculating, a time at which most of the nodules would have already formed on pea, one of the species that they studied. In the early 1990s, Lee and LaRue (1992c) revisited this issue of ethylene and nodulation. These authors designed an experiment where the roots of intact plants and their substrates were treated continuously with very low concentrations of ethylene from the time of inoculation to that of harvest. Concentrations as low as $0.07 \mu \mathrm{L} / \mathrm{L}$ reduced by half the number of nodules formed (Lee and LaRue 1992c). The number of infections was not altered by exogenous ethylene; the step most affected by the treatment was the entry of the rhizobia into the outermost cortical cell layer. Lee and LaRue (1992c) also showed that not all nodulating plants respond to ethylene in the same manner; pea and Melilotus alba annua (sweet clover) were sensitive to the hormone whereas Glycine max (soybean) was not.

\section{Indirect evidence of the action of endogenous ethylene}

None of the studies described above, where ethylene or an ethylene-releasing compound was applied to plants, gave clear evidence that endogenous ethylene acted in the regulation of nodulation. The knowledge of the biosynthetic pathway of ethylene (Fig. 6), the use of ethylene precursors and inhibitors, and the use of plant mutants have allowed researchers to investigate this question.

Use of chemical compounds involved in and (or) interacting with ethylene biosynthesis

ACC, the direct precursor of ethylene (Fig. 6), applied to roots had the same effect as ethylene on nodulation; when added at various times after inoculation to the growth medium of barrel medic, ACC effectively blocked nodulation (Penmetsa and Cook 1997). ACC also reduced nodule number in alfalfa, Lotus japonicus, and Macroptilium atropurpureum (siratro) but not in soybean (Nukui et al. 2000). Conversely, numerous studies with ethylene inhibitors have shown that these compounds repress the inhibitory effect of ethylene on nodulation. For example, Nukui et al. (2000) observed an increase in nodule number when alfalfa, Lotus japonicus, or siratro was treated with either aminoethoxyvinylglycine (AVG), an inhibitor of ACC synthase (Fig. 6), or silver thiosulfate, a compound that releases silver, an antagonist of ethylene action (Fig. 6). Using the properties of ACC and AVG and altering their levels, Oldroyd et al. (2001) were able to modulate the infection frequency and the number of nodules formed on barrel medic; whereas ACC lowers frequency and nodule number, AVG increases them. These results confirmed the findings of Peters and Crist-Estes (1989), Fearn and LaRue (1991), Lee and LaRue (1992a), and Guinel and LaRue (1992) who showed that treating wild-type seedlings with ethylene inhibitors or antagonists consistently, although not always significantly, increased nodule number. Neither of these compounds, however, affected nodulation on soybean (Lee and LaRue 1992c).

The involvement of endogenous ethylene in nodulation has been further demonstrated while studying the infection of Vicia sativa (vetch) subsp. nigra by Rhizobium. Growing the inoculated roots in the light results in the development of an aberrant root morphology and abnormal nodulation characterized respectively by thick short roots (tsr) and unusual location of the nodules (Zaat et al. 1989). It was suggested by van Spronsen et al. (1995) that this $t s r$ phenotype is caused by an overproduction of ethylene. When dark-grown, inoculated vetch roots were treated with ethrel, the same aberrant root and nodulation phenotypes were obtained. In contrast, when the light-grown roots were treated with AVG, nodulation was restored on the primary root (Zaat et al. 1989).

Further evidence, although indirect, demonstrating the involvement of endogenous ethylene in nodulation was uncovered when studying a toxin produced by Bradyrhizobium elkanii. This bacterium synthesizes rhizobitoxine, a chemical that induces leaf chlorosis (e.g., Duodu et al. 1999) and is a potent inhibitor of ACC synthase (Yasuta et al. 1999) (Fig. 6). The toxin plays a promotive role in the nodulation of Vigna radiata (mung bean) (Duodu et al. 1999) and siratro (Yuhashi et al. 2000). In mung bean, the positive 
effect of rhizobitoxine was established by using bacterial mutants unable to synthesize the toxin (Duodu et al. 1999). When the host plants were inoculated with the mutant bacteria, they exhibited nodules arrested at late stages of development, i.e., any stages after NP formation. The nodulation phenotype was partially restored by supplementing the growth medium with AVG or cobalt, an inhibitor of ACC oxidase (Fig. 6) (Duodu et al. 1999). In siratro, rhizobitoxine decreased ethylene evolution whereas the inhibition of its biosynthesis was correlated with an increase in ethylene production and a decrease in nodulation (Yuhashi et al. 2000). It is interesting to note that Bradyrhizobium elkanii infects soybean, mung bean, and siratro, legumes all known to form determinate nodules, i.e., nodules with NP initiating in the outer cortex. To date, the effects of the toxin on legumes forming indeterminate nodules have not been studied.

\section{Use of mutants and transgenic plants}

The inhibitory effects of ethylene on nodulation have been further demonstrated by the use of legume mutants or transgenes characterized as either ethylene insensitive, sensitive, or overproducers. The sickle mutant of barrel medic has been characterized as a hypernodulator, i.e., it forms many more nodules than its parent, possibly because it is unable to regulate the number of infections formed by the rhizobia (Penmetsa and Cook 1997). In addition, sickle does not respond to either ethylene or ACC treatment and appears to be defective in ethylene perception (Penmetsa and Cook 1997). In fact, genetic analysis of sickle demonstrated that its nodulation phenotype and its ethylene insensitivity are determined by a single, recessive allele (Penmetsa and Cook 1997), underlining the involvement of the hormone in the regulation of rhizobial infection.

This correlation between lack of ethylene sensitivity and high nodule number was further confirmed by Gresshoff et al. (2001) who inserted a mutated gene of the Arabidopsis dominant ethylene receptor gene etrl (the product of this gene is located upstream of $c t r l$ in the ethylene transduction pathway; Fig. 6) into the genome of Lotus japonicus. In Arabidopsis, etr1-1 mutants are ethylene insensitive because the transduction of the ethylene signal is lacking. Transgenic Lotus japonicus plants are also ethylene insensitive and they show a novel nodulation phenotype; nodule numbers are increased, much less NP form in front of the root xylem poles ( $70 \%$ in the transgene versus $96 \%$ in the wild-type), and there are twofold more bacteroids per symbiosome (P.M. Gresshoff and D. Lohar, personal communication). Nodule number is proportional to ethylene insensitivity and to transgene expression, i.e., the higher the etrl-1 expression (Northern blots), the higher the seedling growth insensitivity and the larger the nodule number (Gresshoff et al. 2001).

Numerous pleiotropic pea mutants, characterized as low nodulators, are sensitive to ethylene, i.e., their nodulation is restored when their roots are treated with AVG, cobalt, or silver (Fig. 6). The sym5 (Guinel and LaRue 1991) and brz (Guinel and LaRue 1992) mutants form an increased number of nodules on their lateral roots when AVG or silver is applied at the plant crown. Similar results were obtained with sym 21 treated with cobalt or silver; however, although significantly higher, nodule numbers were still low when compared with those of the wild-type (Markwei and LaRue
1997). Nodulation was entirely restored by ethylene inhibitors and antagonists on syml6, a mutant that also exhibits pale-green leaves (Guinel and Sloetjes 2000) and higher concentrations of cytokinins in its roots (B.J. Ferguson and F.C. Guinel, data not shown) and shoots. Interestingly, cytokinin treatments of wild-type pea roots significantly inhibit nodulation and promote root ethylene evolution (Lorteau et al. 2001).

One pea mutant, sym17, is known to be an ethylene overproducer (Lee and LaRue 1992a). This mutant is characterized by short stature and abnormal root growth; furthermore, it has pronounced apical dominance and wrinkled pods. Although it is classified as a low nodulator, its number of nodules is higher than that of the pea mutants previously mentioned. Approximately 60 small nodules formed per root system (compared with 300 in the wild-type); the specific nitrogenase activity of the sym17 nodule is similar to that of the wild-type (Lee and LaRue 1992a). Surprisingly, although sym17 is an overproducer of ethylene, its nodulation phenotype was not normalized by either AVG or silver thiosulfate (Lee and LaRue 1992a).

\section{Effects of ethylene on AM formation}

There is clear evidence for an inhibitory role of exogenous ethylene in this process. However, similarly to the effects of ethylene on nodulation, it is difficult to assign a role for the endogenous levels of the hormone in AM formation and to conclude if AM have any effects on host ethylene production.

\section{Regulation of AM fungal colonization by exogenous ethylene}

Ethylene is primarily regarded as inhibitory to the formation of AM; this effect has been demonstrated in several host-AM fungal combinations. Azcon-Aguilar et al. (1981) first reported decreased colonization in two hosts, alfalfa and Triticum vulgare (wheat), by the AM fungus Glomus mosseae as a result of treating the substrate with ethrel; they found that the intensity of colonization inhibition always increased with increasing concentration of ethrel. Similarly, Morandi (1989) reported that a weekly ethrel soil drench resulted in significant reduction of soybean root colonization by Glomus fasciculatum; this is interesting, since as a partner in the rhizobial symbiosis, soybean appears to be insensitive to ethylene. As mentioned earlier, there are several problems inherent in the use of ethrel as a source of ethylene; one of the most important with respect to AM studies is the release of phosphate, which itself can reduce colonization (Smith and Read 1997) upon ethrel hydrolysis (Abeles et al. 1992). Ishii et al. (1996) applied ethylene gas directly to the substrate; these authors investigated the effects of ethylene on Gigaspora ramisporophora colonization of Poncirus trifoliata (trifoliate orange) roots and found that $1.0 \mu \mathrm{L}$ ethylene/L depressed AM formation. Continuously applying $5.5 \mu \mathrm{L}$ ethylene/L to pea roots colonized by Glomus aggregatum similarly decreased colonization (Geil et al. 2001); the same effect was observed in roots of Allium porrum (leek) colonized by the same AM fungus and exposed to $0.6 \mu \mathrm{L}$ ethylene/L (Geil and Guinel 2002).

Indirect evidence for ethylene as an inhibitor of AM formation also exists. For example, El Ghachtouli et al. (1995) 
suggested that increased colonization of pea by Glomus intraradices after treatment with polyamines could have been, in part, the result of these compounds inhibiting host ethylene production. Also, Nadian et al. (1998) speculated that reduced colonization observed in Trifolium subterraneum (clover) by four different species of Glomus in highly compacted soil might have been the result of increased ethylene production by the physically impeded roots. Interestingly, at a very low concentration $(0.05 \mu \mathrm{L} / \mathrm{L})$, ethylene appears to have a stimulatory effect on AM formation (Ishii et al. 1996). Thus, the concentration of ethylene in the substrate seems to dictate whether this hormone is inhibitory or not.

\section{Effects of AM fungal colonization on host ethylene production}

Several studies have indicated that host ethylene production is altered as a result of the formation of an AM symbiosis. McArthur and Knowles (1992), in their study of Solanum tuberosum (potato) AM formed by G. fasciculatum under different phosphorus availability, were first to report AM-induced alterations in host ethylene production. They demonstrated that colonized roots had lower ACC oxidase activity than noncolonized roots, limiting the capacity of AM roots to produce ethylene. Similarly, Besmer and Koide (1999) reported a decrease in flower ethylene production in Antirrhinum majus (snapdragon) - G. intraradices AM plants. In their study of AM formed between Carica papaya (papaya) and Gigaspora margarita, Cruz et al. (2000) also observed a decrease in ethylene production (despite an increase in ACC) but only in water-stressed AM roots. Thus, there appears to be a trend indicating that host ethylene production is decreased as a result of AM formation, presumably via inhibition of ACC oxidase by a product resulting from AM formation.

In contrast with these findings, Vierheilig et al. (1994) reported that colonization of Lycopersicon esculentum (tomato) by Glomus mosseae did not have any effect on root ethylene production. The findings of Dugassa et al. (1996) further complicate the issue; these authors reported nearly double the ethylene production in roots of Linum usitatissimum (flax) colonized by $G$. intraradices. It should also be noted that in well-irrigated roots, AM fungal colonization increased ethylene production despite no difference in ACC levels between AM and non-AM roots (Cruz et al. 2000). Given the inconsistencies among different AM systems, it is difficult to outline the general effects that AM formation has on host ethylene production; this is perhaps simply due to the differences existing among the host species.

\section{Potential specific roles for ethylene in the symbioses}

Once again, we approach the subject in a chronological manner, from the preinfection stages to the mature structure, but mention only those steps in which ethylene appears to be involved (even in a remote fashion). As in the previous sections, we do not focus on the functioning of these symbioses (e.g., we do not report on the relationships existing between nitrate, phosphate, ethylene, and symbioses). Because there is a paucity of information on the involvement of ethylene in the establishment of AM, this section deals mainly with nodulation; however, in the physiological processes shared by the two symbioses, ethylene probably has a similar action. Here, we felt compelled to incorporate the literature on determinate nodules because it appears that PIT formation and nodule meristem persistence are affected by ethylene in this type of nodule.

\section{Preinfection stages}

\section{Calcium spiking}

Ethylene modulates the NF signal transduction pathway, especially by altering cytosolic calcium spiking (Oldroyd et al. 2001). These authors suggest that the hormone not only determines the sensitivity of the plant to NF but it also defines the nature (strength and frequency) of the calcium spiking response. In addition, ethylene inhibits the maintenance of calcium spiking. Oldroyd et al. (2001) proposed that either the ethylene effect on calcium spiking is linked to the multiple ethylene-regulated effects observed during nodule formation or calcium spiking is one among many steps controlled directly and independently by ethylene. Walker et al. (2000) summarized the correlation existing between nod and myc $^{-}$phenotypes and calcium spiking; a parallel exists between a defect in calcium spiking and these phenotypes, suggesting to us that ethylene would affect calcium responses in both symbioses similarly.

\section{Transient defence response}

Examples of signals generated in plants by the intrusion of pathogens are active oxygen species, ethylene, and SA (e.g., Kombrink and Somssich 1995); although rhizobia and AM fungi are able to ultimately suppress these signals, they are present transiently in infected legume roots. Both active oxygen species (Abeles et al. 1992) and SA (Raskin 1995) are involved in the regulation of ethylene.

In alfalfa at least, rhizobial inoculation results in an oxidative burst producing superoxide and hydrogen peroxide (Santos et al. 2001), which could react nonenzymatically with ACC to promote the production of ethylene (Yang et al. 1990). The localization of superoxide was studied histochemically and the oxidative species was observed as early as in the step of pocket colonization but also in the infection zone of the mature nodule. Santos et al. (2001) suggested that the burst is a prolonged one that could be involved in the regulation of the entire process of infection. Rhizobial superoxide dismutase appears to play a role in the detoxification of superoxide; in alfalfa inoculated with a rhizobial mutant deficient in this enzyme, IT abort quite early in the RH (Santos et al. 2000).

Ethylene production is inhibited by SA through the inhibition of ACC oxidase (Fig. 6) (Raskin 1995); however, SA negatively regulates nodulation as does ethylene. In alfalfa, exogenous application of SA reduces nodule number and delays nodule development, and endogenous SA levels are suppressed upon recognition of the two symbiotic partners (Martínez-Abarca et al. 1998). If either one of the partners has a defect, SA accumulates in the roots; in the alfalfa symbiosis, SA accumulates as early as $4 \mathrm{~h}$ after inoculation with either an incompatible or an NF-deficient Rhizobium (Martínez-Abarca et al. 1998). In the pea symbiosis, a simi- 
lar SA effect is observed; upon recognition between the two symbionts, SA production is reduced. However, when wildtype pea is inoculated with a $\operatorname{Nod} C^{-}$rhizobial mutant, SA levels increase by threefold (Blilou et al. 1999). The sym30 pea mutant also increases SA levels upon inoculation, but it does so even with a proper bacterial partner (Blilou et al. 1999). These authors also studied the evolution of SA in an AM association. In both colonized wild-type and sym30, SA levels increased over time; however, the levels were greater in the mutant.

Ethylene was produced rapidly after rhizobial inoculation of alfalfa (Ligero et al. 1986), vetch (van Workum et al. 1995), and soybean (Suganuma et al. 1995; Ligero et al. 1999) but not in pea cv. Sparkle (Lee and LaRue 1992b; F.C. Guinel, data not shown). In those plants that produced ethylene in response to inoculation, the bacteria were not required because vetch treated with rhizobial NF alone produces ethylene (van Workum et al. 1995). However, the production appears to be specific, since no increase in ethylene production was observed in nonnodulating soybean mutants or in soybean infected with heterologous rhizobia (Suganuma et al. 1995). As aforementioned, AM colonization alters host ethylene production; several studies indicate a decrease in ethylene evolution probably because of a decrease in ACC oxidase activity (e.g., McArthur and Knowles 1992).

\section{Cytoskeleton}

Timmers et al. (1999) very elegantly demonstrated that the Csk of all root tissues responds to the presence of bacteria; the cells of the pericycle, followed by those of the inner cortex, undergo alterations of the microtubular Csk. Later, $\mathrm{RH}$ exhibit a reorganization of their microtubules (Timmers et al. 1999; Catoira et al. 2001) and of their microfilaments (Lhuissier et al. 2001), allowing them to form the wellknown shepherd's crooks.

Several years ago, ethylene was proposed to stabilize microtubules and to promote tubulin polymerization (Steen and Chadwick 1981; Roberts et al. 1985). Ethylene could thus have an indirect effect on cellulose microfibril deposition and act in localized resistance (Abeles et al. 1992). This effect is thought to be important in noncompatible interactions (e.g., Kobayashi et al. 1992), and Timmers (2000) proposed that a similar mechanism is used in compatible interactions; the Csk could affect the deposition of the cellulose microfibrils in such a way that they would not prevent the bacteria from entering the RH. Recent works by Geitmann et al. (1997) and Sugimoto et al. (2000) are obliging us to review the indirect effect(s) of ethylene on cell wall deposition. Geitmann et al. (1997) studied the effect of ethylene evolved from wounded pea roots on microtubule orientation; because AVG (Fig. 6) did not affect the woundinduced rearrangement of the microtubules, these authors concluded that ethylene did not play a role in Csk realignment. Furthermore, in an excellent paper, Sugimoto et al. (2000) questioned the correlation existing between microtubules and cellulose microfibrils; this correlation does not appear to be as tight as what was believed earlier, at least in Arabidopsis roots. The lack of synchrony in the ethylene, microtubules, and cellulose microfibrils path perhaps explains why ethylene does not appear to play a role in $\mathrm{RH}$ deformation induced by NF (Heidstra et al. 1997). The entire problem will have to be revisited keeping in mind that the epidermis could react to ethylene in a manner different from the cortex. In Geitmann et al.'s (1997) study, the epidermis was removed, and therefore, what was studied was the effect of ethylene on the reorientation of microtubules in cortical cells. Better-designed experiments differentiating the epidermis from the cortex are required.

\section{Preinfection thread}

Given its potential effect on the Csk, it is possible that ethylene interacts with PIT development because its establishment relies on Csk rearrangement upon root treatment with NF (Timmers et al. 1999). The peripheral microtubules disassemble and a bundle of endoplasmic microtubules reassemble in the centre of the cell (Timmers et al. 1999). van Spronsen et al. (2001) correlated the presence of PIT with ethylene sensitivity in plants that form determinate nodules; they proposed that Lotus japonicus, which forms PIT, have a higher sensitivity to the hormone than bean, which does not form them. Future work should include the investigation of ethylene effects on PIT formation in plants with indeterminate nodules.

\section{Infection stages}

\section{Colonization}

Ethylene does not appear to inhibit root colonization per se by the microsymbionts. Indirect evidence is given by $\mathrm{brz}$, a low-nodulating pea mutant that has a third less rhizobial infections (Guinel and LaRue 1992) and appressoria (Resendes et al. 2001) than its parent 'Sparkle'. Neither AVG nor silver (Fig. 6) treatment increases the number of rhizobial infections (Guinel and LaRue 1992); the effects of ethylene inhibitors on the number of appressoria formed were not studied. It should be noted that exogenous ethylene may have a direct effect on the fungus causing it to form abnormal appressoria (Geil et al. 2001) reminiscent of morphological alterations observed in several mycorrhizal mutants (e.g., Senoo et al. 2000)

\section{Infection thread}

The bacteria within the IT matrix follow the path of the PIT as the IT grows into the cortex. Ethylene could have a direct effect on the IT progress because it is known to stimulate the enzyme peroxidase (Abeles et al. 1992). Recently, Wisniewski et al. (2000) proposed that peroxidase acts on hydrogen peroxide liberated from the action of diamine oxidase on polyamines and cross-links the glycoproteins of the IT, effectively congealing it and blocking its growth. The authors suggested that such a hardening could play an important role in IT abortion; factors (such as ethylene) known to increase IT abortion could increase the production of peroxidase (Wisniewski et al. 2000). IT abortion is a known natural occurrence that has been demonstrated in pea (Guinel and LaRue 1992) and in barrel medic (Penmetsa and Cook 1997). In mutants of these species, a correlation has been drawn between ethylene sensing and number of aborted IT, suggesting that ethylene is inhibitory to IT growth. In sickle, an ethylene-insensitive mutant of barrel medic, the number of aborted IT is practically nil (Penmetsa and Cook 
1997) whereas in brz, a pea mutant probably oversensitive to ethylene, that number is very high and is reduced upon treatment with ethylene inhibitors (Guinel and LaRue 1992).

Lee and LaRue (1992c) have been able to phenocopy $b r z$ by treating the wild-type 'Sparkle' with exogenous ethylene; most of the IT are arrested in the RH or the bases of these cells. A similar arrest was observed when roots of inoculated 'Sparkle' were grown in dim light (Lee and LaRue 1992b); this inhibitory effect appears to have been mediated by ethylene because silver was able to restore the number of nodules to that found on dark-grown roots. Roots are in fact very sensitive to light; even dim light can stimulate ethylene production in pea (Table 2 in Lee and LaRue 1992b); this light-induced ethylene effect was confirmed in vetch whereby inoculated light-grown roots (tsr plants) had numerous infections aborted, with threads growing very rarely beyond the outermost cortical cell layer (van Spronsen et al. 1995).

\section{Nodule primordium position and formation}

That ethylene is a determinant of NP positioning is a recent finding. Heidstra et al. (1997) very elegantly showed in both pea and vetch how ACC oxidase is expressed only in the inner cortical cells facing the phloem poles of the vascular tissue; these authors were the first to correlate ethylene production and inhibition of NP initiation. Thus, the old observation that nodules generally emerged in front of $x y-$ lem poles can be explained physiologically.

Two pea mutants appear to be affected in the development of NP, and both mutant phenotypes can be rescued by ethylene inhibitors and antagonists. The sym5 mutant exhibits IT growing in the root cortex in a manner similar to that of the parent, but these IT are not associated with cellular divisions (Guinel and LaRue 1991). Silver treatment stimulates inner cortical cells to divide and IT to progress towards NP; however, the total number of nodules formed is still quite low compared with that of the wild-type (Fearn and LaRue 1991; Guinel and LaRue 1991). On the contrary, in sym16, the wild-type nodulation phenotype is totally restored by AVG or silver treatment (Guinel and Sloetjes 2000). The sym16 phenotype is unique in that the IT are twisted and, in general, grow parallel to the root surface; in addition, divisions occur in the cortex, but these are limited to anticlinal divisions, so the primordium appears flat (Guinel and Sloetjes 2000).

\section{Postinfection stages}

Ethylene appears to play a role in controlling the persistence of the nodule meristem. In Sesbania, a semiaquatic tropical legume in which rhizobia enter the root by crack entry (e.g., D'Haeze 2001), determinate and indeterminate nodules can develop on the roots (Fernández-López et al. 1998). Fernández-López et al. (1998) proposed that ethylene is the physiological switch that determines the nodule type; in effect, silver triggers the formation of indeterminate nodules whereas ethrel promotes the development of determinate nodules. Furthermore, the conditions in which the legume grows allow differential ethylene levels to form around the NP. In an aerated support (e.g., vermiculite) where ethylene accumulation will not prevail, indeterminate nodules form whereas in a waterlogged environment known to promote ethylene production, determinate nodules form (Fernández-López et al. 1998).

To date, it is difficult to draw any conclusions on the possible role(s) of ethylene during these late stages. The increase in nodule number observed in the sym 21 pea mutant treated with ethylene inhibitors (Markwei and LaRue 1997) could simply be due to the effect of these compounds on IT growth. Ethylene inhibitors did not appear to have any regulatory effects on sym17, the only known ethylene overproducing pea mutant (Lee and LaRue 1992a).

\section{Hindrances to ethylene studies}

To generalize any results related to ethylene is very difficult. For example, it appears that not all plant cells have the complete biosynthetic apparatus necessary to make ethylene. In mung bean stems, the epidermal cells lack ACC oxidase activity (Todaka and Imaseki 1985), and in the pea variety Argenteum, whereas the leaf mesophyll cells produce ethylene through ACC conversion (i.e., via ACC oxidase), the epidermal cells do not (Osborne 1991). Osborne (1991) suggested that, at least in this genetic line, the epidermis uses an alternative pathway to make the hormone. A possible pathway could be that demonstrated by Mattoo et al. (1986), which involves singlet oxygen obtained from lipid peroxidation and triggered under stress conditions. In addition, hormone sensitivity is known to change depending on the tissue and cells considered (Osborne 1990; Cao et al. 1999) and on the species studied (John 1997). For example, soybean nodulation does not appear to respond to ethylene (Hunter 1993; Schmidt et al. 1999) whereas that of pea does (Lee and LaRue 1992b). It has also been proposed by Smalle and van der Straeten (1997) that specific parts of the cell or of the cell wall could respond differently to ethylene. This could explain why in the nonnodulating sym16 pea mutant, which exhibits altered ethylene sensitivity, only anticlinal divisions are initiated in the NP (Guinel and Sloetjes 2000). Hormones are also known not to act on their own but in concert with other hormones (Abeles et al. 1992). Finally, we want to underline the lack of knowledge on the cellular location of the enzymes (well-defined molecularly) involved in ethylene biosynthesis. Thus, we are not yet certain of the location of ACC oxidase (e.g., John 1997); it appears that the enzyme could be found in the cytoplasm and in the apoplast, although we do not yet know how it crosses the plasma membrane.

The complexity of studying ethylene further increases when one works with symbioses. It is known that the microsymbionts also evolve the hormone, but they do so through pathways different from that of higher plants (Fukuda et al. 1993); however, some bacteria are known to recognize components of the plant pathway and act upon them. For example, several types of Pseudomonas possess the enzyme ACC deaminase that catalyzes the hydrolysis of ACC into ammonia and $\alpha$-ketobutyrate (e.g., Glick et al. 1998).

\section{A model for the involvement of ethylene in the establishment of nodulation}

Strong evidence was given in this review in favour of ethylene being an inhibitor of nodulation; however, a definite and precise role for this plant hormone has yet to be 
determined. Even less is known about the role of ethylene in AM formation, and this is why this final discussion is focused on nodulation. Here, we want to present a hypothesis that we believe takes into consideration most of the data obtained on nodule organogenesis; it will need to be tested by us and others. It can be argued that ethylene is not involved before physical contact is made between the rhizobia and their host because no mutants with defects in the preinfection stages have yet been reported to be ethylene sensitive. However, because ethylene has been shown to affect NF-induced responses such as calcium spiking in the absence of rhizobia, one cannot refute that it could have an indirect role. We propose that $(i)$ the main site of ethylene action is at the interface between the epidermis and the outermost cortical cell layer and (ii) the ethylene effect is dependent on the host species.

\section{The main site of ethylene action is at the epidermis- cortex interface}

Our model is based on two assumptions; the first is that ACC oxidase is not present in epidermal cells, and the second is that these cells are unable to perceive ethylene. Taking these two assumptions into consideration, the first encounter that the bacteria would have with a regulatory level of ethylene would be at the interface between the epidermis and cortex. The cortical tissue would respond to the bacterial presence by converting its ACC into ethylene, perhaps as a component of a transient defence response. The ethylene evolved would move easily into the root intercellular space.

At the root surface per se, there is a control that we believe is independent of ethylene. This control is demonstrated by the existence of nod ${ }^{-}$mutants such as brz (Guinel and LaRue 1992; Resendes et al. 2001), the phenotype of which is not restored by ethylene inhibitors. Also, Lee and LaRue (1992c) demonstrated that exogenous ethylene did not interfere with epidermal entry and IT growth in the RH of wild-type pea plant. Thus, apparently, any rhizobia could enter the epidermis of their appropriate host without an ethylene control.

The microsymbionts, by their physical presence, would act upon the epidermis in a mechanical manner, dictating Csk alterations that would allow the shepherd's crook to form (Catoira et al. 2001). In addition, enzymatic processes would be involved to allow partial degradation of the epidermal wall (Mateos et al. 2001). The rhizobia would enter the $\mathrm{RH}$ and progress within the IT to the epidermis. It is at the interface of the epidermis and outermost cortical cell layer that a tight control exists; this control is exemplified by the pea mutant brz (Guinel and LaRue 1992; Resendes et al. 2001), the barrel medic mutant sickle (Penmetsa and Cook 1997), and the Lotus japonicus mutant Ljsym4-1 (Bonfante et al. 2000). We propose that this checkpoint is under ethylene control; the regulation of this checkpoint will depend on the levels of ethylene synthesized in the cortex and probably present in the apoplast.

At this point, the fate of the infection would be decided depending on the levels of ethylene (Lee and LaRue 1992c) within the intercellular spaces. If these were low (less than $0.07 \mu \mathrm{L} / \mathrm{L}$ in pea), infection would be prone to progress with the help of the reorganized Csk (Timmers 2000) and the pre- viously formed PIT (van Brussel et al. 1992) in the cortex. Higher levels of the hormone (e.g., $45 \mu \mathrm{L} / \mathrm{L}$ in pea) would trigger enzymes such as peroxidase that would solidify the IT matrix and prevent further growth of the IT (Wisniewski et al. 2000); this implies the existence of a signal other than ethylene moving from the apoplast to the epidermal symplast. In natural conditions, the two processes responsible for either the success or the failure of IT growth could occur simultaneously to autoregulate infection.

The ability of the cortex to make ethylene, and conversely the incapacity of the epidermis to do so, fits with our hypothesis of having two programs for nodule organogenesis. The cortical program would be directly responsive to ethylene. NF, once added to the roots, would trigger ethylene biosynthesis in the outer cortical cells where the hormone would act on the Csk allowing the formation of PIT. In the inner cortical cells, the hormone would alter the auxin to cytokinin ratio by either inhibiting auxin transport (Abeles et al. 1992) or regulating its activity or distribution (Luschnig et al. 1998); this ratio alteration would stimulate the nodule progenitor cells to divide. On the other hand, the epidermal program would not be directly regulated by ethylene because of the assumed lack of perception of this hormone by the epidermis. Some ethylene would also be released in the apoplast of the cortex; the fate of the infection would depend on the levels of the hormone found there. Thus, direct effects of ethylene in the cortex would result in a cascade of events indirectly affecting the epidermis. The Csk rearrangement in the epidermis (triggered by the rhizobia) will need to be coordinated with that of the Csk in the cortex (triggered by the chemical presence of the NF); the match between the rearranged Csk of the two different types of cells would have to be tightly orchestrated in the symplast. A mismatch could lead to abortion of the infection.

\section{The ethylene effect is dependent on the species}

Although we know a great deal about the ethylene biosynthetic pathway and transduction pathway in higher plants, much remains a mystery about this simple hormone (John 1997). For example, it is not understood why nodulation in soybean appears to be insensitive to ethylene (Lee and LaRue 1992c; Schmidt et al. 1999). Since the mode of entry can be quite diverse depending on the subfamilies of the species (Fig. 4), it is possible that the response of the legumes to ethylene will also be diverse.

The nodulation of Sesbania is a good example that demonstrates how ethylene can have different effects (D'Haeze 2001). As mentioned above, in this species, nodules can form on the roots or on the stems, although the stem nodules are in fact found on adventitious roots emerging from the stem. Rhizobia enter the root by crack entry at the site of root emergence (Fig. 4E). For nodules to form in Sesbania, axillary RH and infection pockets, formed by local plant cell death, are required. D'Haeze (2001) showed that ethylene, hydrogen peroxide, and NF are required for these two events; calcium appears to be needed also. He proposed that NF triggers an oxidative burst in the root, which will be responsible for ethylene and hydrogen peroxide production. These two compounds formed in the extracellular space induce plant cell death in the inner cortex of the root and the formation of infection pockets; these steps are required for 
the initiation of an NP. Therefore, ethylene is essential for this species to nodulate. What is also interesting is that the epidermis is not necessary here; the cortical cells are the target for the NF and the rhizobia.

Thus, it would be worthwhile to look at many more legume species and study the effects of ethylene on their nodulation. We agree with Sprent and de Faria (1988); the iceberg we are studying has many tips and we have just begun to unravel the physiology of the establishment of the symbioses, and this only in a few species.

\section{Acknowledgements}

We would like to thank Brett Ferguson, Dr. Janet Sprent, Dr. David Barker, and two anonymous reviewers for their critical reading of the manuscript and for their helpful comments. We also would like to thank Drs. Marcelle Holsters, Alexey Borisov, and Peter Gresshoff for having supplied preprints and unpublished information. F.C.G. is indebted to Dr. Thomas LaRue who for the last 10 years or so has always been willing to share his ideas and time. F.C.G. thanks members of her laboratory for the work they provided that helped build the models. Research on pea mutants in F.C.G.'s laboratory is supported by a Natural Sciences and Engineering Research Council of Canada operating grant and by several internal grants provided by Wilfrid Laurier University. F.C.G. would also like to thank the European Union (project HPCT-CT-1999-00015) for its financial help that allowed her to attend the Molecular Genetics of Model Legumes Euro-Conference in Gölm, Germany, where she was able to discuss her ideas with numerous persons. This field of research is huge and it is easy to overlook articles; the authors are sorry if they have omitted to mention some work.

\section{References}

Abeles, F.B., Morgan, P.W., and Saltveit, M.E. 1992. Ethylene in plant biology. 2nd ed. Academic Press, San Diego, Calif.

Albrecht, C., Geurts, R., Lapeyrie, F., and Bisseling, T. 1998. Endomycorrhizae and rhizobial Nod factors both require SYM8 to induce the expression of the early nodulin genes PSENOD5 and PsENOD12A. Plant J. 15: 605-614.

Albrecht, C., Geurts, R., and Bisseling, T. 1999. Legume nodulation and mycorrhizae formation; two extremes in host specificity meet. EMBO J. 18: 281-288.

Ardourel, M., Demont, N., Debellé, F., Maillet, F., de Billy, F., Promé, J.C., Dénarié, J., and Truchet, G. 1994. Rhizobium meliloti lipooligosaccharide nodulation factors: different structural requirements for bacterial entry into target root hair cells and induction of plant symbiotic developmental responses. Plant Cell, 6: 1357-1374.

Azcon-Aguilar, C., Rodriguez-Navarro, D.N., and Barea, J.M. 1981. Effects of ethrel on the formation and responses to VA mycorrhiza in Medicago and Triticum. Plant Soil, 60: 461-468.

Balaji, B., Ba, A.M., LaRue, T.A., Tepfer, D., and Piché, Y. 1994. Pisum sativum mutants insensitive to nodulation are also insensitive to invasion by the mycorrhizal fungus Gigaspora margarita. Plant Sci. 102: 195-203.

Balestrini, R., Hahn, M.G., Faccio, A., Mendgen, K., and Bonfante, P. 1996. Differential localization of carbohydrate epitopes in plant cell walls in the presence and absence of arbuscular mycorrhizal fungi. Plant Physiol. 111: 203-213.

Barker, D.G., Bianchi, S., Blondon, F., Dattée, Y., Duc, G., Essad, S., Flament, P., Gallusci, P., Génier, G., Guy, P., Muel, X., Tourneur, J., Dénarié, J., and Huguet, T. 1990. Medicago truncatula, a model plant for studying the molecular genetics of the Rhizobium-legume symbiosis. Plant Mol. Biol. Rep. 8: 40-49.

Barker, S.J., and Tagu, D. 2000. The roles of auxins and cytokinins in mycorrhizal symbioses. J. Plant Growth Regul. 19: 144-154.

Barker, S.J., Tagu, D., and Delp, G. 1998. Regulation of root and fungal morphogenesis in mycorrhizal symbioses. Plant Physiol. 116: 1201-1207.

Barnes, D.K., Vance, C.P., Heichel, G.H., Peterson, M.A., and Ellis,W.R. 1988. Registration of a non-nodulation and three ineffective nodulation alfalfa germplasms. Crop Sci. 28: 721-722.

Bauer, P., Ratet, P., Crespi, M.D., Schultze, M., and Kondorosi, A. 1996. Nod factors and cytokinins induce similar cortical cell division, amyloplast deposition and MsEnod12A expression patterns in alfalfa roots. Plant J. 10: 91-105.

Besmer, Y.L., and Koide, R.T. 1999. Effect of mycorrhizal colonization and phosphorus on ethylene production by snapdragon (Antirrhinum majus L.) flowers. Mycorrhiza, 9: 161-166.

Blancaflor, E.B., Zhao, L., and Harrison, M.J. 2001. Microtubule organization in root cells of Medicago truncatula during development of an arbuscular mycorrhizal symbiosis with Glomus versiforme. Protoplasma, 217: 154-165.

Blilou, I., Ocampo, J.A., and Garcia-Garrido, J.M. 1999. Resistance of pea roots to endomycorrhizal fungus or Rhizobium correlates with enhanced levels of endogenous salicylic acid. J. Exp. Bot. 50: 1663-1668.

Bonfante, P., and Perotto, S. 1995. Strategies of arbuscular mycorrhizal fungi when infecting host plants. New Phytol. 130: 3-21.

Bonfante, P., Genre, A., Faccio, A., Martini, I., Schauser, L., Stougaard, J., Webb, J., and Parniske, M. 2000. The Lotus japonicus LjSym4 gene is required for the successful symbiotic infection of root epidermal cells. Mol. Plant-Microbe Interact. 13: $1109-1120$.

Boogerd, F.C., and van Rossum, D. 1997. Nodulation of groundnut by Bradyrhizobium: a simple infection process by crack entry. FEMS Microbiol. Rev. 21: 5-27.

Borisov, A.Y., Morzhina, E.V., Kulikova, O.A., Tchetkova, S.A., Lebsky, V.K., and Tikhonovich, I.A. 1992. New symbiotic mutants of pea (Pisum sativum L.) affecting either nodule initiation or symbiosome development. Symbiosis, 14: 297-313.

Borisov, A.Y., Rozov, S.M., Tsyganov, V.E., Morzhina, E.V., Lebsky V.K., and Tikhonovich, I.A. 1997. Sequential functioning of sym13 and sym31, two genes affecting symbiosome development in root nodules of pea (Pisum sativum L.). Mol. Gen. Genet. 254: 592-598.

Borisov, A.Y., Barmicheva, E.M., Jacobi, L.M., Tsyganov, V.E., Voroshilova, V.A., and Tikhonovich, I.A. 2000. Pea (Pisum sativum L.) mendelian genes controlling development of nitrogen-fixing nodules and arbuscular mycorrhiza. Czech. J. Genet. Plant Breed. 36: 106-110.

Brewin, N.J. 1991. The legume root nodule. Annu. Rev. Cell Biol. 7: 191-226.

Brewin, N.J. 1998. Tissue and cell invasion by Rhizobium: the structure and development of infection threads and symbiosomes. In The Rhizobiaceae: molecular biology of model plant-associated bacteria. Edited by H.P. Spaink, A. Kondorosi, and P.J.J. Hooykaas. Kluwer Academic Publishers, Dordrecht, Netherlands. pp. 417-429. 
Buée, M., Rossignol, M., Jauneau, A., Ranjeva, R., and Bécard, G. 2000. The pre-symbiotic growth of arbuscular mycorrhizal fungi is induced by a branching factor partially purified from plant root exudates. Mol. Plant-Microbe Interact. 13: 693-698.

Caetano-Anolles, G. 1997. Molecular dissection and improvement of the nodule symbiosis in legumes. Field Crops Res. 53: 47-68.

Cao, X.F., Linstead, P., Berger, F., Kieber, J., and Dolan, L. 1999. Differential ethylene sensitivity of epidermal cells are involved in the establishment of cell pattern in the Arabidopsis root. Physiol. Plant. 106: 311-317.

Cardenas, L., Holdaway-Clarke, T.L., Sanchez, F., Quinto, C., Feijó, J.A., Kunkel, J.G., and Hepler, P.K. 2000. Ion changes in legume root hairs responding to Nod factors. Plant Physiol. 123: 443-451.

Carroll, B.J., McNeil, D.L., and Gresshoff, P.M. 1986. Mutagenesis of soybean (Glycine $\max$ (L.) Merr.) and the isolation of nonnodulating mutants. Plant Sci. 47: 109-114.

Catoira, R., Galera, C., de Billy, F., Penmetsa, R.V., Journet, E.-P, Maillet, F., Rosenberg, C., Cook, D., Gough, C., and Dénarié, J. 2000. Four genes of Medicago truncatula controlling components of a Nod factor transduction pathway. Plant Cell, 12: $1647-1665$.

Catoira, R., Timmers, A.C.J., Maillet, F., Galera, C., Penmetsa, R.V., Cook, D., Dénarié, J., and Gough, C. 2001. The $H C L$ gene of Medicago truncatula controls Rhizobium-induced root hair curling. Development, 128: 1507-1518.

Cavagnaro, T.R., Gao, L.-L., Smith, F.A., and Smith, S.E. 2001. Morphology of arbuscular mycorrhizas is influenced by fungal identity. New Phytol. 151: 469-475.

Chang, C., and Shockey, J.A. 1999. The ethylene-response pathway: signal perception to gene regulation. Curr. Opin. Plant Biol. 2: 352-358.

Charon, C., Johansson, C., Kondorosi, E., Kondorosi, A., and Crespi, M. 1997. enod40 induces dedifferentiation and division of root cortical cells in legumes. Proc. Natl. Acad. Sci. U.S.A. 94: 8901-8906.

Ciardi, J., and Klee, H. 2001. Regulation of ethylene-mediated responses at the level of the receptor. Ann. Bot. 88: 813-822.

Cohn, J., Day, B., and Stacey, G. 1997. Legume nodule organogenesis. Trends Plant Sci. 3: 105-110.

Cook, D., Dreyer, D., Bonnet, D., Howell, M., Nony, E., and VandenBosch, K. 1995. Transient induction of a peroxidase gene in Medicago truncatula precedes infection by Rhizobium meliloti. Plant Cell, 7: 43-55.

Cruz, A.F., Ishii, T., and Kadoya, K. 2000. Effects of arbuscular mycorrhizal fungi on tree growth, leaf water potential, and levels of 1-aminocyclopropane-1-carboxylic acid and ethylene in the roots of papaya under water-stress conditions. Mycorrhiza, 10: $121-123$.

Davidson, A.L., and Newcomb, W. 2001a. Changes in actin microfilament arrays in developing pea root nodule cells. Can. J. Bot. 79: 767-776.

Davidson, A.L., and Newcomb, W. 2001b. Organization of microtubules in developing pea root nodule cells. Can. J. Bot. 79: 777-786.

de Faria, S.M., Hay, G.T., and Sprent, J.I. 1988. Entry of rhizobia into roots of Mimosa scabrella Bentham occurs between epidermal cells. J. Gen. Microbiol. 134: 2291-2296.

de Faria, S.M., de Lima, H.C., Olivares, F.L., Melo, R.B., and Xavier, R.P. 1999. Nodulação em espécies florestais, especificidade hospedeira e implicações na sistemática de Leguminosae. In Inter-relação fertilidade, biologia do solo e nutrição de plantas. Edited by J.O. Siqueira, F.M.S. Moreira, A.S. Lopes, L.R.G. Guilherme, V. Faquin, A.E. Furtini Neto, and
J.G. Carvalho. Sociedade Brasileira de Ciência do Solo Universidade federal de Lavras, Departamento de Ciência do Solo. pp. 667-686.

Dehio, C., and de Bruijn, F.J. 1992. The early nodulin gene SrEnod2 from Sesbania rostrata is inducible by cytokinin. Plant J. 2: $117-128$.

D'Haeze, W. 2001. Signaling during nodule initiation on the tropical legume Sesbania rostrata. Ph.D. thesis, Department of Plant Genetics, University of Gent, Belgium.

Drennan, D.S.H., and Norton, C. 1972. The effect of ethrel on nodulation in Pisum sativum L. Plant Soil, 36: 53-57.

Duc, G., and Messager, A. 1989. Mutagenesis of pea (Pisum sativum L.) and the isolation of mutants for nodulation and nitrogen fixation. Plant Sci. 60: 207-213.

Duc, G., Trouvelot, A., Gianinazzi-Pearson, V., and Gianinazzi, S. 1989. First report of non-mycorrhizal plant mutants $\left(\mathrm{Myc}^{-}\right)$ obtained in pea (Pisum sativum L.) and fababean (Vicia faba L.). Plant Sci. 60: 215-222.

Dugassa, G.D., von Alten, H., and Schönbeck, F. 1996. Effects of arbuscular mycorrhiza (AM) on health of Linum usitatissimum L. infected by fungal pathogens. Plant Soil, $\mathbf{1 8 5}$ : 173-182.

Duodu, S., Bhuvaneswari, T.V., Stokkermans, T.J.W., and Peters, N.K. 1999. A positive role for rhizobitoxine in Rhizobiumlegume symbiosis. Mol. Plant-Microbe Interact. 12: 1082-1089.

Ehrhardt, D.W., Wais, R., and Long, S.R. 1996. Calcium spiking in plant root hairs responding to Rhizobium nodulation signals. Cell, 85: 673-681.

Ekdahl, I. 1953. Studies on the growth and the osmotic conditions of root hairs. Symb. Bot. Ups. XI: 57-87.

El Ghachtouli, N., Paynot, M., Morandi, D., Martin-Tanguy, J., and Gianinazzi, S. 1995. The effect of polyamines on endomycorrhizal infection of wild type Pisum sativum, cv. Frisson $\left(\right.$ nod $\left.^{+} \mathrm{myc}^{+}\right)$and two mutants $\left(\operatorname{nod}^{-} \mathrm{myc}^{+}\right.$and $\left.\operatorname{nod}^{-} \mathrm{myc}^{-}\right)$. Mycorrhiza, 5: 189-192.

Emons, A.M., and Mulder, B. 2000. Nodulation factors trigger an increase of fine bundles of subapical actin filaments in Vicia root hairs: implications for root hair curling around bacteria. In Biology of plant-microbe interactions. Vol. 2. Proceedings of the 9th International Congress on Molecular Plant-Microbe Interactions, Amsterdam, Netherlands, 25-30 July 1999. Edited by J.G.M. de Wit, T. Bisseling, and W.J. Stiekema. International Society for Molecular Plant-Microbe Interactions, St. Paul, Minn. pp. 272-276.

Engvild, K.C. 1987. Nodulation and nitrogen fixation mutants of pea, Pisum sativum. Theor. Appl. Genet. 74: 711-713.

Fahn, A. 1986. Plant anatomy. 3rd ed. Pergamon Press, Oxford, England.

Fang, Y., and Hirsch, A.M. 1998. Studying early nodulin gene ENOD40 expression and induction by nodulation factor and cytokinin in transgenic alfalfa. Plant Physiol. 116: 53-68.

Fearn, J.C., and LaRue, T.A. 1991. Ethylene inhibitors restore nodulation to sym5 mutants of Pisum sativum L. cv Sparkle. Plant Physiol. 96: 239-244.

Felle, H.H., Kondorosi, E., Kondorosi, A., and Schultze, M. 1995. Nod signal-induced plasma membrane potential changes in alfalfa root hairs are differentially sensitive to structural modifications of the lipo-chitooligosaccharide. Plant J. 7: 939-947.

Felle, H.H., Kondorosi, E., Kondorosi, A., and Schultze, M. 1996. Rapid alkalinization in alfalfa root hairs in response to rhizobial lipochitooligosaccharide signals. Plant J. 10: 295-301.

Fernández-López, M., Goormachtig, S., Gao, M., D’Haeze, W., Van Montagu, M., and Holsters, M. 1998. Ethylene-mediated 
phenotypic plasticity in root nodule development on Sesbania rostrata. Proc. Natl. Acad. Sci. U.S.A. 95: 12724 - 12728.

Fuchs, Y., and Lieberman, M. 1968. Effects of kinetin, IAA, and gibberellin on ethylene production, and their interactions in growth of seedlings. Plant Physiol. 43: 2029-2036.

Fukuda, H., Ogawa, T., and Tanase, S. 1993. Ethylene production by micro-organisms. Adv. Microb. Physiol. 35: 275-306.

Gallaud, I. 1905. Études sur les mycorhizes endotrophes. I. Historique et introduction. Rev. Gén. Bot. 17: 5-48.

Garriock, M.L., Peterson, R.L., and Ackerley, C.A. 1989. Early stages in colonization of Allium porrum (leek) roots by the vesicular-arbuscular mycorrhizal fungus, Glomus versiforme. New Phytol. 112: 85-92.

Geil, R.D., and Guinel, F.C. 2002. Effects of elevated substrateethylene on colonization of leek (Allium porrum) by the arbuscular mycorrhizal fungus Glomus aggregatum. Can. J. Bot. 80: $114-119$.

Geil, R.D., Peterson, R.L., and Guinel, F.C. 2001. Morphological alterations of pea (Pisum sativum cv. Sparkle) arbuscular mycorrhizas as a result of exogenous ethylene treatment. Mycorrhiza, 11: 137-143.

Geitmann, A., Hush, J.M., and Overall, R.L. 1997. Inhibition of ethylene biosynthesis does not block microtubule re-orientation in wounded pea roots. Protoplasma, 198: 135-142.

Genre, A., and Bonfante, P. 1997. A mycorrhizal fungus changes microtubule orientation in tobacco root cells. Protoplasma, 199: $30-38$.

Genre, A., and Bonfante, P. 2002. Epidermal cells of a symbiosisdefective mutant of Lotus japonicus show altered cytoskeleton organisation in the presence of a mycorrhizal fungus. Protoplasma, 219: 43-50.

Geurts, R., Heidstra, R., Hadri, A., Downie, J.A., Franssen, H., van Kammen, A., and Bisseling, T. 1997. Sym2 of pea is involved in a nodulation factor-perception mechanism that controls the infection process in the epidermis. Plant Physiol. 115: 351-359.

Gianinazzi-Pearson, V. 1996. Plant cell responses to arbuscular mycorrhizal fungi: getting to the roots of the symbiosis. Plant Cell, 8: 1871-1883.

Gianinazzi-Pearson, V., Gianinazzi, S., Guillemin, J.P., Trouvelot, A., and Duc, G. 1991. Genetic and cellular analysis of resistance to vesicular arbuscular (VA) mycorrhizal fungi in pea mutants. In Advances in molecular genetics of plantmicrobe interactions. Edited by H. Hennecke and D.P.S. Verma. Kluwer Academic Publishers, Dordrecht, Netherlands. pp. 336-342.

Giovannetti, M., Avio, L., Sbrana, C., and Citernesi, A.S. 1993. Factors affecting appressorium development in the vesicular-arbuscular mycorrhizal fungus Glomus mosseae (Nicol. \& Gerd.) Gerd., and Trappe. New Phytol. 123: 115-122.

Giovannetti, M., Sbrana, C., Citernesi, A.S., and Avio, L. 1996. Analysis of factors involved in fungal recognition responses to host-derived signals by arbuscular mycorrhizal fungi. New Phytol. 133: 65-71.

Glick, B.R., Penrose, D.M., and Li, J. 1998. A model for the lowering of plant ethylene concentrations by plant growthpromoting bacteria. J. Theor. Biol. 190: 63-68.

Gollotte, A., Gianinazzi-Pearson, V., Giovannetti, M., Sbrana, C., Avio, L., and Gianinazzi, S. 1993. Cellular localization and cytochemical probing of resistance reactions to arbuscular mycorrhizal fungi in a 'locus a' myc' mutant of Pisum sativum L. Planta, 191: 112-122.

Goodlass, G., and Smith, K.A. 1979. Effects of ethylene on root extension and nodulation of pea (Pisum sativum L.) and white clover (Trifolium repens L.). Plant Soil, 51: 387-395.
Gremaud, M.F., and Harper, J.E. 1989. Selection and initial characterization of partially nitrate tolerant nodulation mutants of soybean. Plant Physiol. 89: 169-173.

Gresshoff, P.M., Stiller, J., Maguire, T., Lohar, D., Laniya, S., Buzas, D., Habamunga, S., Smith, L., Carroll, B., Searle, I., Meksem, K., Lightfoot, D., Grimmond, S., and Men, A.E. 2001. Integrated functional genomics to define the plant's function in symbiotic nodulation. In 13th International Congress on Nitrogen Fixation Proceedings, Hamilton, Ont., July 2-7, 2001. McMaster University, Hamilton, Ont. pp. 1-4.

Grobbelaar, N., Clarke, B., and Hough, M.C. 1971. The nodulation and nitrogen fixation of isolated roots of Phaseolus vulgaris $\mathrm{L}$. III. The effect of carbon dioxide and ethylene. Plant Soil Spec. pp. 215-223.

Guinel, F.C., and Hirsch, A.M. 2000. The involvement of root hairs in mycorrhizal associations. In Root hairs: cell and molecular biology. Edited by R.W. Ridge and A.M.C. Emons. SpringerVerlag, Tokyo, Japan. pp. 285-310.

Guinel, F.C., and LaRue, T.A. 1991. Light microscopy study of nodulation initiation in Pisum sativum L. cv Sparkle and its lownodulating mutant E2 (sym 5). Plant Physiol. 97: 1206-1211.

Guinel, F.C., and LaRue, T.A. 1992. Ethylene inhibitors partly restore nodulation to pea mutant E107 (brz). Plant Physiol. 99: 515-518.

Guinel, F.C., and Sloetjes, L.L. 2000. Ethylene is involved in the nodulation phenotype of Pisum sativum R50 (sym16), a pleiotropic mutant that nodulates poorly and has pale green leaves. J. Exp. Bot. 51: 885-894.

Hadri, A.-E., and Bisseling, T. 1998. Responses of the plant to Nod factors. In The Rhizobiaceae: molecular biology of model plantassociated bacteria. Edited by H.P. Spaink, A. Kondorosi, and P.J.J. Hooykaas. Kluwer Academic Publishers, Dordrecht, Netherlands. pp. 403-416.

Hall, M.A., Smith, A.R., Novikova, G.V., and Moshkov, I.E. 1999. Ethylene signal transduction in relation to hormone sensitivity. Plant Biol. 1: 46-56.

Hamilton, A.J., Bouzayen, M., and Grierson, D. 1991. Identification of a tomato gene for the ethylene-forming enzyme by expression in yeast. Proc. Natl. Acad. Sci. U.S.A. 88: 7434-7437.

Harrison, M.J. 1999. Molecular and cellular aspects of the arbuscular mycorrhizal symbiosis. Annu. Rev. Plant Physiol. Plant Mol. Biol. 50: 361-389.

Heidstra, R., Yang, W.C., Yalcin, Y., Peck, S., Emons A.-M., van Kammen, A., and Bisseling, T. 1997. Ethylene provides positional information on cortical cell division but is not involved in Nod factor-induced root hair tip growth in Rhizobium-legume interaction. Development, 124: 1781-1787.

Hirayama, T., and Alonso, J.M. 2000. Ethylene captures a metal! Metal ions are involved in ethylene perception and signal transduction. Plant Cell Physiol. 41: 548-555.

Hirsch, A.M. 1992. Developmental biology of legume nodulation. New Phytol. 122: 211-237.

Hirsch, A.M., and Fang, Y. 1994. Plant hormones and nodulation: what's the connection? Plant Mol. Biol. 26: 5-9.

Hirsch, A.M., and Kapulnik, Y. 1998. Signal transduction pathways in mycorrhizal associations: comparisons with the Rhizobium-legume symbiosis. Fungal Genet. Biol. 23: 205-212.

Hirsch, A.M., and LaRue, T.A. 1997. Is the legume nodule a modified root or stem or an organ sui generis? Crit. Rev. Plant Sci. 16: $361-392$.

Hirsch, A.M., Fang, Y., Asad, S., and Kapulnik, Y. 1997. The role of phytohormones in plant-microbe symbioses. Plant Soil, 194: 171-184. 
Hua, J., and Meyerowitz, E.M. 1998. Ethylene responses are negatively regulated by a receptor gene family in Arabidopsis thaliana. Cell, 94: 261-271.

Hunter, W.J. 1993. Ethylene production by root nodules and effect of ethylene on nodulation in Glycine max. Appl. Environ. Microbiol. 59: 1947-1950.

Ishii, T., Shrestha, Y.H., Matsumoto, I., and Kadoya, K. 1996. Effect of ethylene on the growth of vesicular-arbuscular mycorrhizal fungi and on the mycorrhizal formation of trifoliate orange roots. J. Jpn. Soc. Hortic. Sci. 65: 525-529.

John, P. 1997. Ethylene biosynthesis: the role of 1aminocyclopropane-1-carboxylate (ACC) oxidase, and its possible evolutionary origin. Physiol. Plant. 100: 583-592.

Johnson, P.R., and Ecker, J.R. 1998. The ethylene gas signal transduction pathway: a molecular perspective. Annu. Rev. Genet. 32: 227-254.

Joshi, P.A., Caetano-Anolles, G., Graham, E.T., and Gresshoff, P.M. 1991. Ontogeny and ultrastructure of spontaneous nodules in alfalfa (Medicago sativa). Protoplasma, 162: 1-11.

Kneen, B.E., and LaRue, T.A. 1988. Induced symbiosis mutants of pea (Pisum sativum) and sweetclover (Melilotus alba annua). Plant Sci. 58: 177-182.

Kneen, B.E., LaRue, T.A., Hirsch, A.M., Smith, C.A., and Weeden, N.F. 1990. sym13: a gene conditioning ineffective nodulation in Pisum sativum. Plant Physiol. 94: 899-905.

Kneen, B.E., Weeden, N.F., and LaRue, T.A. 1994. Non-nodulating mutants of Pisum sativum (L.) cv. Sparkle. J. Hered. 85: 129-133.

Kobayashi, I., Kobayashi, Y., Yamaoka, N., and Kunoh, H. 1992. Recognition of a pathogen and a non-pathogen by barley coleoptile cells. III. Responses of microtubules and actin filaments in barley coleoptile cells to penetration attempts. Can. J. Bot. 70: $1815-1823$.

Kolchinsky, A., Funke, R, and Gresshoff, P.M. 1994. Dissecting molecular mechanisms of nodulation: taking a leaf from Arabidopsis. Plant Mol. Biol. 26: 549-552.

Kombrink, E., and Somssich, I.E. 1995. Defense responses of plants to pathogens. Adv. Bot. Res. 21: 1-34.

LaRue, T.A., and Weeden, N.F. 1994. The symbiosis genes of the host. In Proceedings of the First European Nitrogen Fixation Congress. Edited by G. Kiss and G. Endre. Officina Press, Szeged, Hungary. pp. 147-151.

Lee, K.H., and LaRue, T.A. 1992a. Pleiotropic effects of sym-17: a mutation in Pisum sativum L. cv Sparkle causes decreased nodulation, altered root and shoot growth, and increased ethylene production. Plant Physiol. 100: 1326-1333.

Lee, K.H., and LaRue, T.A. 1992b. Ethylene as a possible mediator of light- and nitrate-induced inhibition of nodulation of Pisum sativum L. cv Sparkle. Plant Physiol. 100: 1334-1338.

Lee, K.H., and LaRue, T.A. 1992c. Exogenous ethylene inhibits nodulation of Pisum sativum L. cv Sparkle. Plant Physiol. 100: 1759-1763.

Le Gal, M.F., and Hobbs, S.L.A. 1989. Cytological studies of the infection process in nodulating and non-nodulating pea genotypes. Can. J. Bot. 67: 2435-2443.

Lhuissier, F.G.P., De Ruijter, N.C.A., Sieberer, B.J., Esseling, J.J., and Emons, A.M.C. 2001. Time course of cell biological events evoked in legume root hairs by Rhizobium Nod factors: state of the art. Ann. Bot. 87: 289-302.

Ligero, F., Lluch, C., and Olivares, J. 1986. Evolution of ethylene from roots of Medicago sativa plants inoculated with Rhizobium meliloti. J. Plant Physiol. 125: 361-365.

Ligero, F., Poveda, J.L., Gresshoff, P.M., and Caba, J.M. 1999. Nitrate- and inoculation-enhanced ethylene biosynthesis in soy- bean roots as a possible mediator of nodulation control. J. Plant Physiol. 154: 482-488.

Lorteau, M.-A., Ferguson, B.J., and Guinel, F.C. 2001. Effects of cytokinin on ethylene production and nodulation in pea (Pisum sativum) cv. Sparkle. Physiol. Plant. 112: 421-428.

Ludwig-Müller, J. 2000. Hormonal balance in plants during colonization by mycorrhizal fungi. In Arbuscular mycorrhizas: physiology and function. Edited by Y. Kapulnik and D.D. Douds, Jr. Kluwer Academic Publishers, Dordrecht, Netherlands. pp. 263-285.

Luschnig, C., Gaxiola, R.A., Grisafi, P., and Fink, G.R. 1998. EIR1, a root-specific protein involved in auxin transport, is required for gravitropism in Arabidopsis thaliana. Genes Dev. 12: 2175-2187.

Lynch, J., and Brown, K.M. 1997. Ethylene and plant responses to nutritional stress. Physiol. Plant. 100: 613-619.

Madsen, L.H., Borisov, A.Y., Tsyganov, V.E., Voroshilova, V.A., Batagov, A.O., Umehara,Y., Schauser, L., Sandal, N., Ellis, N., Tikhonovich, I.A., and Stougaard, J. 2001. The pea sym35 gene is a homolog of Lotus Nin: characterization of three sym35 mutant alleles. In Molecular genetics of model legumes: impact for legume biology and breeding. Proceedings of the 2nd EuroConference on model legumes, Gölm, Germany, 15-19 September 2001. p. 90.

Markwei, C.M., and LaRue, T.A. 1992. Phenotypic characterization of sym 8 and sym 9 , two genes conditioning non-nodulation in Pisum sativum 'Sparkle'. Can. J. Microbiol. 38: 548-554.

Markwei, C.M., and LaRue, T.A. 1997. Phenotypic characterization of sym21, a gene conditioning shoot-controlled inhibition of nodulation in Pisum sativum cv. Sparkle. Physiol. Plant. 100: 927-932.

Marsh, J.F., and Schultze, M. 2001. Analysis of arbuscular mycorrhizas using symbiosis-defective plant mutants. New Phytol. 150: 525-532.

Martínez-Abarca, F., Herrera-Cervera, J.A., Bueno, P., Sanjuan, J., Bisseling, T., and Olivares, J. 1998. Involvement of salicylic acid in the establishment of the Rhizobium meliloti - alfalfa symbiosis. Mol. Plant-Microbe Interact. 11: 153-155.

Mateos, P.F., Baker, D.L., Petersen, M., Velazquez, E., Jimenez-Zurdo, J.I., Martinez-Molina, E., Squartini, A., Orgambide, G., Hubbell, D.H., and Dazzo, F.B. 2001. Erosion of root epidermal cell walls by Rhizobium polysaccharide-degrading enzymes as related to primary host infection in the Rhizobium-legume symbiosis. Can. J. Microbiol. 47: 475-487.

Mathesius, U., Bayliss, C., Weinman, J.J., Schlaman, H.R.M., Spaink, H.P., Rolfe, B.G., McCully, M.E., and Djordjevic, M.A. 1998. Flavonoids synthesized in cortical cells during nodule initiation are early developmental markers in white clover. Mol. Plant-Microbe Interact. 11: 1223-1232.

Mathesius, U., Weinman, J.J., Rolfe, B.G., and Djordjevic, M.A. 2000. Rhizobia can induce nodules in white clover by 'hijacking' mature cortical cells activated during lateral root development. Mol. Plant-Microbe Interact. 13: 170-182.

Matsubara, Y., Uetake, Y., and Peterson, R.L. 1999. Entry and colonization of Asparagus officinalis roots by arbuscular mycorrhizal fungi with emphasis on changes in host microtubules. Can. J. Bot. 77: 1159-1167.

Matthysse, A.G., and McMahan, S. 2001. The effect of the Agrobacterium tumefaciens attR mutation on attachment and root colonization differs between legumes and other dicots. Appl. Environ. Microbiol. 67: 1070-1075.

Mattoo, A.K., Baker, J.E., and Moline, H.E. 1986. Induction by copper ions of ethylene production in Spirodela oligorrhiza: 
evidence for a pathway independent of 1-aminocyclo-propane1-carboxylic acid. J. Plant Physiol. 123: 193-202.

McArthur, D.A.J., and Knowles, N.R. 1992. Resistance responses of potato to vesicular-arbuscular mycorrhizal fungi under varying abiotic phosphorus levels. Plant Physiol. 100: 341-351.

Morandi, D. 1989. Effect of xenobiotics on endomycorrhizal infection and isoflavonoid accumulation in soybean roots. Plant Physiol. Biochem. 27: 697-701.

Mort, A.J., and Grover, P.B., Jr. 1988. Characterization of root hair cell walls as potential barriers to the infection of plants by bacteria. The carbohydrate component. Plant Physiol. 86: 638-641.

Morzhina, E.V., Tsyganov, V.E., Borisov, A.Y., Lebsky, V.K., and Tikhonovich, I.A. 2000. Four developmental stages identified by genetic dissection of pea (Pisum sativum L.) root nodule morphogenesis. Plant Sci. 155: 75-83.

Mylona, P., Pawlowski, K., and Bisseling, T. 1995. Symbiotic nitrogen fixation. Plant Physiol. 7: 869-885.

Nadian, H., Smith, S.E., Alston, A.M., Murray, R.S., and Siebert, B.D. 1998. Effects of soil compaction on phosphorus uptake and growth of Trifolium subterraneum colonized by four species of vesicular-arbuscular mycorrhizal fungi. New Phytol. 139: $155-165$.

Nagahashi, G., and Douds, D.D., Jr. 1997. Appressorium formation by AM fungi on isolated cell walls of carrot roots. New Phytol. 136: 299-304.

Niebel, A., Gressent, F., Bono, J.-J., Ranjeva, R., and Cullimore, J. 1999. Recent advances in the study of Nod factor perception and signal transduction. Biochimie, 81: 669-674.

Nukui, N., Ezura, H., Yuhashi, K.-I., Yasuta, T., and Minamisawa, K. 2000. Effects of ethylene precursor and inhibitors for ethylene biosynthesis and perception on nodulation in Lotus japonicus and Macroptilium atropurpureum. Plant Cell Physiol. 41: 893-897.

Oldroyd, G.E.D., Engstrom, E.M., and Long, S.R. 2001. Ethylene inhibits the Nod factor signal transduction pathway of Medicago truncatula. Plant Cell, 13: 1835-1849.

Osborne, D.J. 1984. Concepts of target cells in plant differentiation. Cell Differ. 14: 161-169.

Osborne, D.J. 1990. Ethylene formation, cell types and differentiation. In Polyamines and ethylene: biochemistry, physiology, and interactions. Edited by H.E. Flores, R.N. Arteca, and J.C. Shannon. American Society of Plant Physiologists, St. Paul, Minn. pp. 203-215.

Osborne, D.J. 1991. Ethylene in leaf ontogeny and abscission. In The plant hormone ethylene. Edited by A.K. Mattoo and J.C. Suttle. CRC Press Inc., Boca Raton, Fla. pp. 193-214.

Park, S.J., and Buttery, B.R. 1988. Nodulation mutants of white bean (Phaseolus vulgaris L.) induced by ethyl-methane sulphonate. Can. J. Plant Sci. 68: 199-202.

Parniske, M. 2000. Intracellular accommodation of microbes by plants: a common developmental program for symbiosis and disease? Curr. Opin. Plant Biol. 3: 320-328.

Paruvangada, V.G., and Davis, T.M. 1999. A dominant, host plant mutation conferring ineffective nodulation in the chickpeaRhizobium symbiosis. J. Hered. 90: 297-299.

Pawlowski, K. 1997. Nodule-specific gene expression. Physiol. Plant. 99: 617-631.

Penmetsa, R.V., and Cook, D.R. 1997. A legume ethyleneinsensitive mutant hyperinfected by its rhizobial symbiont. Science (Washington, D.C.), 275: 527-530.

Peters, N.K., and Crist-Estes, D.K. 1989. Nodule formation is stimulated by the ethylene inhibitor amino-ethoxyvinylglycine. Plant Physiol. 91: 690-693.
Peterson, R.L., and Farquhar, M.L. 1994. Mycorrhizas: integrated development between roots and fungi. Mycologia, 86: 311-326.

Peterson, R.L., and Guinel, F.C. 2000. The use of plant mutants to study regulation of colonization by AM fungi. In Arbuscular mycorrhizas: physiology and function. Edited by Y. Kapulnik and D.D. Douds Jr. Kluwer Academic Publishers, Dordrecht, Netherlands. pp. 147-171.

Postma, J.G., Jacobsen, E., and Feenstra, W.J. 1988. Three pea mutants with an altered nodulation studied by genetic analysis and grafting. J. Plant Physiol. 132: 424-430.

Provorov, N.A., Borisov, A.Y., and Tikhonovich, I.A. 2002. Developmental genetics and evolution of symbiotic structures in nitrogen-fixing nodules and arbuscular mycorrhiza. J. Theor. Biol. 214: $215-232$.

Rae, A.L., Bonfante-Fasolo, P., and Brewin, N.J. 1992. Structure and growth of infection threads in the legume symbiosis with Rhizobium leguminosarum. Plant J. 2: 385-395.

Raskin, I. 1995. Salicylic acid. In Plant hormones. Physiology, biochemistry and molecular biology. Edited by P.J. Davies, Kluwer Academic Publishers, Dordrecht, Netherlands. pp. 188-205.

Reddy, A.S.N. 2001. Calcium: silver bullet in signaling. Plant Sci. 160: $381-404$.

Resendes, C.M., Geil, R.D., and Guinel, F.C. 2001. Mycorrhizal development in a low nodulating pea mutant. New Phytol. 150: 563-572.

Roberts, I.N., Lloyd, C.W., and Roberts, K. 1985. Ethyleneinduced microtubule reorientations: mediation by helical arrays. Planta, 164: 439-447.

Rodriguez, F.I., Esch, J.J., Hall, A.E., Binder, B.M., Schaller, G.E., and Bleecker, A.B. 1999. A copper cofactor for the ethylene receptor ETR1 from Arabidopsis. Science (Washington, D.C.), 283: 996-998.

Sagan, M., Huguet, T., and Duc, G. 1994. Phenotypic characterization and classification of nodulation mutants of pea (Pisum sativum L.). Plant Sci. 100: 59-70.

Sagan, M., Morandi, D., Tarenghi, E., and Duc, G. 1995. Selection of nodulation and mycorrhizal mutants in the model plant Medicago truncatula (Gaertn.) after $\gamma$-ray mutagenesis. Plant Sci. 111: 63-71.

Salzer, P., Bonanomi, A., Beyer, K., Vogeli-Lange, R., Aeschbacher, R.A., Lange, J., Wiemken, A., Kim, D., Cook, D.R., and Boller, T. 2000. Differential expression of eight chitinase genes in Medicago truncatula roots during mycorrhiza formation, nodulation, and pathogen infection. Mol. PlantMicrobe Interact. 13: 763-777.

Santos, R., Hérouart, D., Sigaud, S., Puppo, A., and Touati, D. 2000. Critical protective role of bacterial superoxide dismutase in Rhizobium-legume symbiosis. Mol. Microbiol. 38: 750-759.

Santos, R., Hérouart, D., Sigaud, S., Touati, D., and Puppo, A. 2001. Oxidative burst in alfalfa: Sinorhizobium meliloti symbiotic interaction. Mol. Plant-Microbe Interact. 14: 86-89.

Schauser, L., Handberg, K., Sandal, N., Stiller, J., Thykjaer, T., Pajuelo, E., Nielsen, A., and Stougaard, J. 1998. Symbiotic mutants deficient in nodule establishment identified after T-DNA transformation of Lotus japonicus. Mol. Gen. Genet. 259: 414-423.

Schmidt, J.S., Harper, J.E., Hoffman, T.K., and Bent, A.F. 1999. Regulation of soybean nodulation independent of ethylene signaling. Plant Physiol. 119: 951-959.

Schneider, A., Walker, S.A., Poyser, S., Sagan, M., Ellis, T.H.N., and Downie, J.A. 1999. Genetic mapping and functional analysis of a nodulation-defective mutant (sym19) of pea (Pisum sativum L.). Mol. Gen. Genet. 262: 1-11.

Schultze, M., and Kondorosi, A. 1998. Regulation of symbiotic root nodule development. Annu. Rev. Genet. 32: 33-57. 
Sen, D., and Weaver, R.W. 1984. A basis for different rates of $\mathrm{N}_{2^{-}}$ fixation by the same strains of Rhizobium in peanut and cowpea root nodules. Plant Sci. Lett. 34: 239-246.

Senoo, K., Solaiman, M.Z., Kawaguchi, M., Imaizumi-Anraku, H., Akao, S., Tanaka, A., and Obata, H. 2000. Isolation of two different phenotypes of mycorrhizal mutants in the model legume plant Lotus japonicus after EMS-treatment. Plant Cell Physiol. 41: 726-732.

Smalle, J., and van der Straeten, D. 1997. Ethylene and vegetative development. Physiol. Plant. 100: 593-605.

Smith, F.A., and Smith, S.E. 1997. Structural diversity in (vesicular)arbuscular mycorrhizal symbioses. New Phytol. 137: 373-388.

Smith, S.E., and Read, D.J. 1997. Mycorrhizal symbiosis. 2nd ed. Academic Press, San Diego, Calif.

Solano, R., and Ecker, J.R. 1998. Ethylene gas: perception, signaling and response. Curr. Opin. Plant Biol. 1: 393-398.

Sprent, J.I. 2002. Knobs, knots and nodules: the renaissance in legume symbiosis research. New Phytol. 153: 2-5.

Sprent, J.I., and de Faria, S.M. 1988. Mechanisms of infection of plants by nitrogen fixing organisms. Plant Soil, 110: 157-165.

Sprent, J.I., and Raven, J.A. 1992. Evolution of nitrogen-fixing symbioses. In Biological nitrogen fixation. Edited by G. Stacey, R.H. Burris, and H.J. Evans. Chapman and Hall, New York. pp. 461-496.

Steen, D.A., and Chadwick, A.V. 1981. Ethylene effects in pea stem tissue. Evidence of microtubule mediation. Plant Physiol. 67: 460-466.

Stougaard, J. 2000. Regulators and regulation of legume root nodule development. Plant Physiol. 124: 531-540.

Stougaard, J. 2001. Genetics and genomics of root symbiosis. Curr. Opin. Plant Biol. 4: 328-335.

Subba-Rao, N.S., Mateos, P.F., Baker, D., Pankratz, H.S., Palma, J., Dazzo, F.B., and Sprent, J.I. 1995. The unique rootnodule symbiosis between Rhizobium and the aquatic legume, Neptunia natans (L f.) Druce. Planta, 196: 311-320.

Suganuma, N., Yamauchi, H., and Yamamoto, K. 1995. Enhanced production of ethylene by soybean roots after inoculation with Bradyrhizobium japonicum. Plant Sci. 111: 163-168.

Sugimoto, K., Williamson, R.E., and Wasteneys, G.O. 2000. New techniques enable comparative analysis of microtubule orientation, wall texture, and growth rate of intact roots of Arabidopsis. Plant Physiol. 124: 1493-1506.

Szczyglowski, K., Shaw, R.S., Wopereis, J., Copeland, S., Hamburger, D., Kasiborski, B., Dazzo, F.B., and de Bruijn, F.J. 1998. Nodule organogenesis and symbiotic mutants of the model legume Lotus japonicus. Mol. Plant-Microbe Interact. 11: 684-697.

Theologis, A. 1998. Ethylene signalling: redundant receptors all have their say. Curr. Biol. 8: R875-R878.

Timmers, A.C.J. 2000. Infection of root hairs by rhizobia: infection thread development with emphasis on the microtubular cytoskeleton. In Root hairs: cell and molecular biology. Edited by R.W. Ridge and A.M.C. Emons. Springer-Verlag, Tokyo, Japan. pp. 223-239.

Timmers, A.C.J., Auriac, M.-C., de Billy, F., and Truchet, G. 1998. Nod factor internalization and microtubular cytoskeleton changes occur concomitantly during nodule differentiation in alfalfa. Development, 125: 339-349.

Timmers, A.C.J., Auriac, M.-C., and Truchet, G. 1999. Refined analysis of early symbiotic steps of the Rhizobium-Medicago interaction in relationship with microtubular cytoskeleton rearrangements. Development, 126: 3617-3628.

Todaka, I., and Imaseki, H. 1985. Epidermal cells do not contribute to auxin-induced ethylene production in mung bean stem sections. Plant Cell Physiol. 26: 865-871.
Tsyganov, V.E., Morzhina, E.V., Stefanov, S.Y., Borisov, A.Y., Lebsky, V.K., and Tikhonovich, I.A. 1998. The pea (Pisum sativum L.) genes sym 33 and sym 40 control infection thread formation and root nodule function. Mol. Gen. Genet. 259: 491-503.

Tsyganov, V.E., Voroshilova, V.A., Kukalev, A.S., Azarova, T.S., Yakobi, L.M., Borisov, A.Y., and Tikhonovich, I.A. 1999. Pisum sativum L. genes sym14 and sym35 control infection thread growth initiation during the development of symbiotic nodules. Russ. J. Genet. 35: 284-291.

Tsyganov, V.E., Voroshilova, V.A., Priefer, U.B., Borisov, A.Y., and Tikhonovich, I.A. 2002. Genetic dissection of the initiation of the infection process and nodule tissue development in the Rhizobium-pea (Pisum sativum L.) symbiosis. Ann. Bot. 89: 357-366.

van Brussel, A.A.N., Bakhuizen, R., van Spronsen, P.C., Spaink, H.P., Tak, T., Lugtenberg, B.J.J., and Kijne, J.W. 1992. Induction of pre-infection thread structures in the leguminous host plant by mitogenic lipo-oligosaccharides of Rhizobium. Science (Washington, D.C.), 257: 70-72.

van de Sande, K., Pawlowski, K., Czaja, I., Wieneke, U., Schell, J., Schmidt, J., Walden, R., Matvienko, M., Wellink, J., Van Kamme, A., Franssen, H., and Bisseling, T. 1996. Modification of phytohormone response by a peptide encoded by ENOD40 of legumes and a nonlegume. Science (Washington, D.C.), 273: 370-373.

van Rhijn, P., Fang, Y., Galili, S., Shaul, O., Atzmon, N., Wininger, S., Eshead, Y., Lum, M., Li, Y., To, V., Fujishige, N., Kapulnik, Y., and Hirsch, A.M. 1997. Expression of early nodulin genes in alfalfa mycorrhizae indicates that signal transduction pathways used in forming arbuscular mycorrhizae and Rhizobium-induced nodules may be conserved. Proc. Natl. Acad. Sci. U.S.A. 94: 5467-5472.

van Spronsen, P.C., Bakhuizen, R., van Brussel, A.A.N., and Kijne, J.W. 1994. Cell wall degradation during infection thread formation by the root nodule bacterium Rhizobium leguminosarum is a two-step process. Eur. J. Cell Biol. 64: 88-94.

van Spronsen, P.C., van Brussel, A.A.N., and Kijne, J.W. 1995. Nod factors produced by Rhizobium leguminosarum biovar viciae induce ethylene-related changes in root cortical cells of Vicia sativa ssp. nigra. Eur. J. Cell Biol. 68: 463-469.

van Spronsen, P.C., Grønlund, M., Pacios Bras, C., Spaink, H.P., and Kijne, J.W. 2001. Cell biological changes of outer cortical root cells in early determinate nodulation. Mol. Plant-Microbe Interact. 14: 839-847.

van Workum, W.A.T., van Brussel, A.A.N., Tak, T., Wijffelman, C.A., and Kijne, J.W. 1995. Ethylene prevents nodulation of Vicia sativa ssp. nigra by exopolysaccharidedeficient mutants of Rhizobium leguminosarum bv. viciae. Mol. Plant-Microbe Interact. 8: 278-285.

Vasse, J., de Billy, F., Camut, S., and Truchet, G. 1990. Correlation between ultrastructural differentiation of bacteroids and nitrogen fixation in alfalfa nodules. J. Bacteriol. 172: 4295-4306.

Vasse, J., de Billy, F., and Truchet, G. 1993. Abortion of infection during the Rhizobium meliloti - alfalfa symbiotic interaction is accompanied by a hypersensitive reaction. Plant J. 4: 555-566.

Vega-Hernandez, M.C., Pérez-Galdona, R., Dazzo, F.B., Jarabo-Lorenzo, A., Alfayate, M.C., and León-Barrios, M. 2001. Novel infection process in the indeterminate root nodule symbiosis between Chamaecytisus proliferus (tagasaste) and Bradyrhizobium sp. New Phytol. 150: 707-721.

Vernoud, V., Journet, E.P., and Barker, D.G. 1999. MtENOD20, a Nod factor-inducible molecular marker for root cortical cell activation. Mol. Plant-Microbe Interact. 12: 604-614. 
Vierheilig, H., Alt, M., Mohr, U., Boller, T., and Wiemken, A. 1994. Ethylene biosynthesis and activities of chitinase and $\beta$ 1,3-glucanase in the roots of host and non-host plants of vesicular-arbuscular mycorrhizal fungi after inoculation with Glomus mosseae. J. Plant Physiol. 143: 337-343.

Vogel, J.P., Woeste, K.E., Theologis, A., and Kieber, J.J. 1998. Recessive and dominant mutations in the ethylene biosynthetic gene ACS5 of Arabidopsis confer cytokinin insensitivity and ethylene overproduction, respectively. Proc. Natl. Acad. Sci. U.S.A. 95: 4766-4771.

Voroshilova, V.A., Boesten, B., Tsyganov, V.E., Borisov, A.Y., Tikhonovich, I.A., and Priefer, U.B. 2001. Effect of mutations in Pisum sativum L. genes blocking different stages of nodule development on the expression of late symbiotic genes in Rhizobium leguminosarum bv. viciae. Mol. Plant-Microbe Interact. 14: 471-476.

Wais, R.J., Galera, C., Oldroyd, G., Catoira, R., Penmetsa, R.V., Cook, D., Gough, C., Dénarié, J., and Long, S.R. 2000. Genetic analysis of calcium spiking responses in nodulation mutants of Medicago truncatula. Proc. Natl. Acad. Sci. U.S.A. 97: 13407 13412.

Walker, S.A., Viprey, V., and Downie, J.A. 2000. Dissection of nodulation signaling using pea mutants defective for calcium spiking induced by Nod factors and chitin oligomers. Proc. Natl. Acad. Sci. U.S.A. 97: 13413 - 13418.

Wegel, E., Schauser, L., Sandal, N., Stougaard, J., and Parniske, M. 1998. Mycorrhiza mutants of Lotus japonicus define genetically independent steps during symbiotic infection. Mol. Plant-Microbe Interact. 11: 933-936.

Wisniewski, J.-P., Rathbun, E.A., Knox, J.P., and Brewin, N.J. 2000. Involvement of diamine oxidase and peroxidase in insolubilization of the extracellular matrix: implications for pea nodule initiation by Rhizobium leguminosarum. Mol. PlantMicrobe Interact. 13: 413-420.

Yang, S.F., Yip, W.K., and Dong, J.G. 1990. Mechanism and regu- lation of ethylene biosynthesis. In Polyamines and ethylene: biochemistry, physiology, and interactions. Edited by H.E. Flores, R.N. Arteca, and J.C. Shannon. American Society of Plant Physiologists, St. Paul, Minn. pp. 24-35.

Yang, W.-C., Katinakis, P., Hendriks, P., Smolders, A., de Vries, F., Spee, J., van Kammen, A., Bisseling, T., and Franssen, H. 1993. Characterization of GmENOD40, a gene showing novel patterns of cell-specific expression during soybean nodule development. Plant J. 3: 573-585.

Yang, W.-C., de Blank, C., Meskiene, I., Hirt, H., Bakker, J., van Kammen, A., Franssen, H., and Bisseling, T. 1994. Rhizobium Nod factors reactivate the cell cycle during infection and nodule primordium formation, but the cycle is only completed in primordium formation. Plant Cell, 6: 1415-1426.

Yasuta, T., Satoh, S., and Minamisawa, K. 1999. New assay for rhizobitoxine based on inhibition of 1-amino-cyclopropane-1carboxylate synthase. Appl. Environ. Microbiol. 65: 849-852.

Young, J.P.W., and Johnston, A.W.B. 1989. The evolution of specificity in the legume-Rhizobium symbiosis. Trends Ecol. Evol. 4: 341-349.

Yuhashi, K.-I., Ichikawa, N., Ezura, H., Akao, S., Minakawa, Y., Nukui, N., Yasuta, T., and Minamisawa, K. 2000. Rhizobitoxine production by Bradyrhizobium elkanii enhances nodulation and competitiveness on Macroptilium atropurpureum. Appl. Environ. Microbiol. 66: 2658-2663.

Zaat, S.A.J., van Brussel, A.A.N., Tak, T., Lugtenberg, B.J.J., and Kijne, J.W. 1989. The ethylene-inhibitor aminoethoxyvinylglycine restores normal nodulation by Rhizobium leguminosarum biovar viciae on Vicia sativa subsp. nigra by suppressing the 'thick and short roots' phenotype. Planta, 177: 141-150.

Zhou, L., Jang, J.-C., Jones, T.L., and Sheen, J. 1998. Glucose and ethylene signal transduction crosstalk revealed by an Arabidopsis glucose-insensitive mutant. Proc. Natl. Acad. Sci. U.S.A. 95: 10294 - 10299. 